\title{
A forging method for reducing process steps in the forming of automotive fasteners
}

Senyong Chen ${ }^{a}$, Yi Qin ${ }^{a}{ }^{*}$, J.G. Chen ${ }^{b}$ and Chee-Mun Choy ${ }^{b} \&$

${ }^{a}$ Design, Manufacture and Engineering Management, University of Strathclyde, 75 Montrose Street, Glasgow G1 1XJ, UK

${ }^{b}$ Ritia (Shanghai) Auto Standard Component Co Ltd, Shanghai, China ${ }^{c}$ Eagle Metalware Co., Ltd. No.268, Yuyang Road, Kunshan, China. 


\section{Graphic abstract}
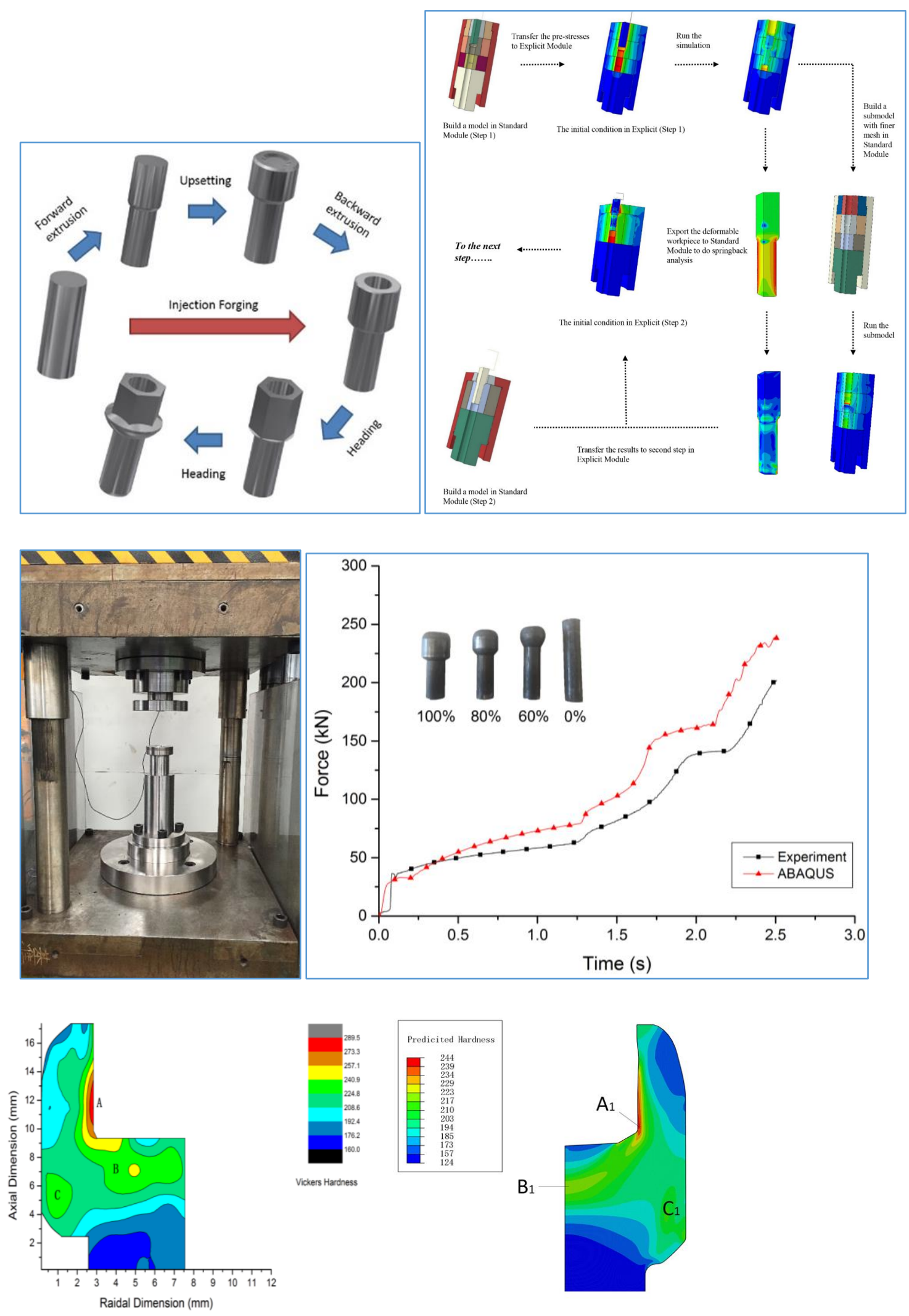

(a). Measured

(b). Simulated 


\section{Highlights}

- Reducing process steps in automotive fastener production

- Using injection forging to achieve combined material flows

- Examining forming force/energy requirements, material properties and forming quality

- Concluding the feasibility of Injection Forging for the fasteners production for process step reduction

- Recommending process deployment and tool-design considerations 


\begin{abstract}
The automotive component manufacturing sector is experiencing fierce competitions. To enable improvements in production efficiency, the authors introduced single step injection forging as an alternative to conventional multisteps forging processes for manufacturing automobile fasteners, being enabled by a dedicated tool-design to achieve combined materialflows and hence, a complex component-form. To assist in this, a feasibility study was conducted, including comparisons of conventional multisteps forging with injection forging, through FE simulations, experimental validation of the injection forging process, as well as detailed examinations of the quality of the parts formed. The simulations were focused mainly on the forming of a wheel bolt. Axi-symmetric models were developed to analyse forging force and energy requirements, resulting forming-errors and tool stresses for each process. Injection forging tests were carried out in a factory environment with the aim of verifying the FE results and of confirming process and tool-design feasibility. Based on the results from these studies, the feasibility of replacing multisteps forging with injection forging was confirmed. It was established that injection forging may demand higher a forming force in its single step but it would consume less energy. Also, there is less chance of developing flow faults during injection forging, which is critical for the forming of the automotive fasteners. Nevertheless, due to the complex material-flow in injection forging and large die-deflections, a dedicated tool-design for compensating for forming-errors and for enhancing tool-life has to be enabled for the forging production applications.
\end{abstract}

Keywords: Automotive fasteners, Multisteps forging, Injection forging, FE analysis, Forming experiment. 


\section{Introduction}

Over the past several decades, the growing automobile industry has increased its demand for components. In order to meet this demand for parts of various sizes and shapes, conventional processes such as forging, machining and casting have been used [1]. Among them, cold forging as an efficient process from which dimensionally accurate parts can be made plays an important role. Cold forging can result in components with enhanced mechanical properties [2]. Although machining, warm and hot forging have been widely used for the forming of automotive parts, cold forging is still a priority choice for manufacturers when it is feasible for practical production.

However, with increasing global competition, conventional cold forging processes are facing challenges. This is due largely to the demand from customers who require components with high-precision and a stable quality, using high strength-to-weight ratio materials. On the other hand, industry also needs to reduce cost and improve efficiency against other competitors. As one of the efforts to meet these requirements, injection forging is being researched as a new option from which complex components can be obtained in a minimum number of forging steps.

Injection forging was originally introduced by the National Engineering Laboratory, UK [3]. Compared with other forging processes,producing similarly shaped parts, such as heading, extrusion or flange forging, this method was shown to be more efficient. Because of the lack of useful theoretical analyses for injection forging, Parsons et al. [4] employed upper band analysis to study forging of thin flanges. It was argued that this method could describe the process accurately when materials were treated as ideal plastic materials. Another attempt on injection forging was to forge axisymmetric tubular materials. Some remarkable studies in this area were carried out by Dieterle [5] and Hendry et al. [6]. They analysed different defect types in injection forged tubes, using physical models and experiments.

From the 1980 s to 2000 , finite element (FE) analysis was developed into a popular tool to analyse metal forming processes. Using FE analysis, Balendra and Qin published several studies on injection forging [7-9]. Within these studies, they comprehensively defined the forming limits and summarised the failure-forms of products. Additionally, they introduced a pressure-assisted forging process for thick-walled tubes. With the assistance of pressurising media, hollow parts were successfully obtained [10-11]. They also analysed the pressure losses in the injection chamber. It was reported that the pressure could drop $40 \%-60 \%$ in the 
injection chamber because of a large friction force that was generated [12]. Later, using different lubricants was evaluated to examine the pressure transmission efficiency. Ma et al. [13] extended the previous work of Qin's to examine the effectiveness of rubber and polyethene, as pressurizing media in pressure-assisted injection forging. Rubber performed better than polyethene in tubular forming, regarding the large elasticity of the rubber which leads to easier material flow and hence, supporting the tube better as a pressurising media. This is essential for large deformations to be achieved for the tube as well as for forming complex component-shapes. Other similar studies also included forming of solid and hollowflanged parts, universal joints and gears [14-17].

In the research reported in this paper, it was proposed, by authors, to introduce injection forging as a new forging method to reduce the forging steps in automotive fasteners production, through combining material-flows in a single-stroke forging, such as combining material-flows in the redial and vertical direction as well as forward and backward flows, being enabled by a dicated tool design to realise the process concept with desired material flows. The use of injection forging, nevertheless, does raise some issues concerning tool life and component accuracy. Because of the reduced number of the forging steps, a tool may experience more severe stresses than that in the conventional forging. The increased tool stresses may promote crack growth which would reduce tool life. These stresses may also lead to the increased tool deflections, which could influence component accuracy. These issues were addressed in detail in the study reported in this paper with a view to confirming the feasibity of this forging method for the forming of automotive fasteners.

\section{Methodology for FE Simulations and Experiments}

\subsection{Process configuration}

Fig. 1 illustrates a conventional multisteps forging process for making hexagon headed bolts. The billet experiences five deformation steps. In the first operation, the round bar is extruded forwards to reduce the diameter of the shank. Then, it is upset in the second operation. Next, the head is backward extruded to form a cavity. The hexagon head is formed and finished in the last two operations.

To shorten the process chain, injection forging is proposed. It is intended to combine the first three operations shown in Fig. 1 into one operation. The process concept is shown in Fig. 2, 
which uses a floating-die design. In this design, the die insert supported on a spring, moves together with the punch, both at the same velocity. The counter-punch is stationery during forming and supports the billet until the final form is achieved. It then moves upwards to eject the part from the die. In this way, the initial billet is formed directly into the intermediate product with a cavity by radial and backwards metal flow.

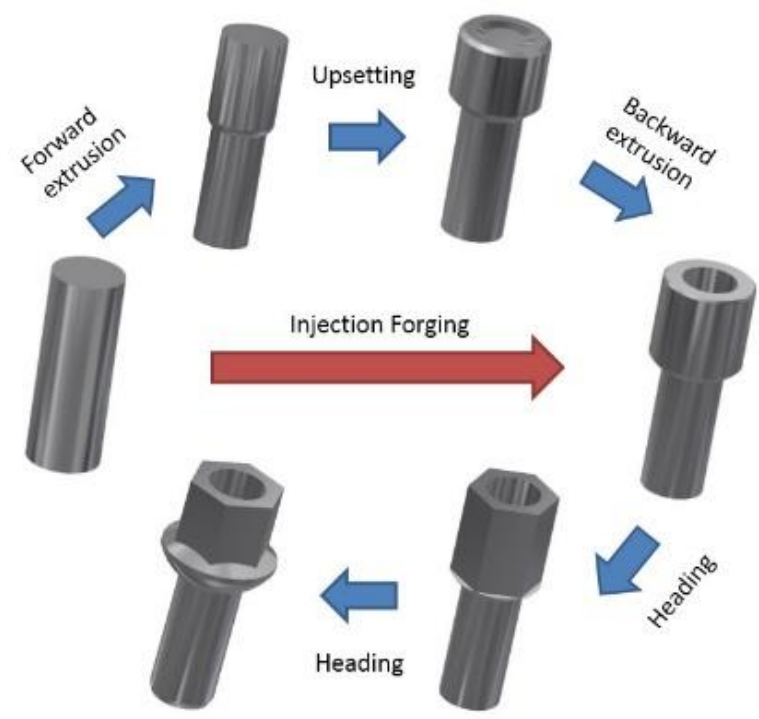

Fig. 1: Illustration of the traditional forging process and the injection forging process.

The initial geometries of the workpiece and the targeted component size for two forging processes used in FE simulations and experiments are illustrated in Fig. 3. To get the full size of the final product, the volume of the initial workpiece must be equal to that of the targeted component. The volume was calculated as $7789.16 \mathrm{~mm}^{3}$. 


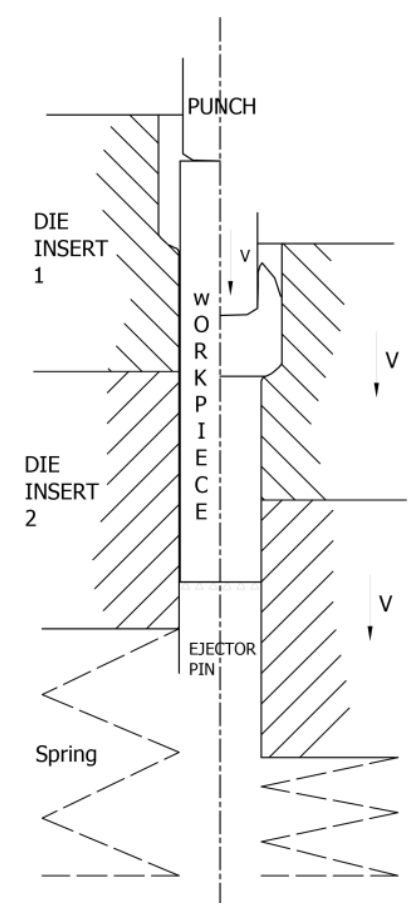

Fig. 2: Illustration of the injection forging process used for the forming of the bolt.

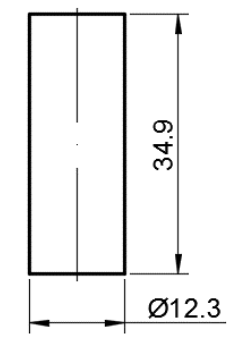

Initial Workpiece for Multistep Forging

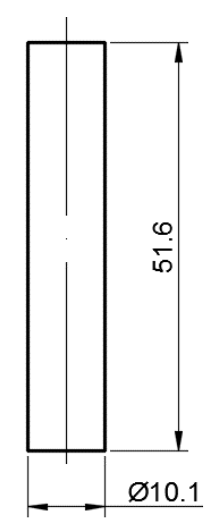

Initial Workpiece for Injection Forging

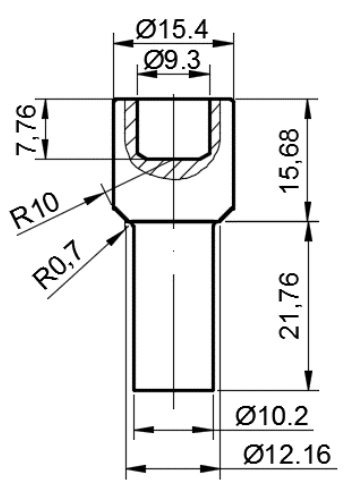

Intermediate Component

Fig. 3: The targeted component dimension and initial workpiece dimension for multisteps forging and injection forging.

\subsection{FE simulation models}

Two FE software packages, ABAQUS and DEFORM, were used. DEFORM uses rigidplastic material models and is equipped with efficient auto-remeshing capability which is ideal for the simulation of the forming of complex-shaped components with acceptable computational efficiency. ABAQUS uses elastic-pastic materials models enabling analysis of tool and material deflection and tool stress and strain and hence, provides conveniency for evaluating component accuracy and tool-stressing state (and hence, lead to examining the tool-life). Combined uses of two software codes resultd in efficient comparison of two formin 
processes and detailing evaluation of the performance of injection forging for fastner production.

Axi-symmetric models (refer to Fig. 4) were developed in ABAQUS. In simulations, the punch and ejector pin were set to be rigid bodies, while the other parts were treated as elasticplastic bodies. In contrast to the model in ABAQUS, the tool in DEFORM, shown in Fig.5, was defined as rigid, and only the workpiece was treated as deformable, that is rigid-plastic.

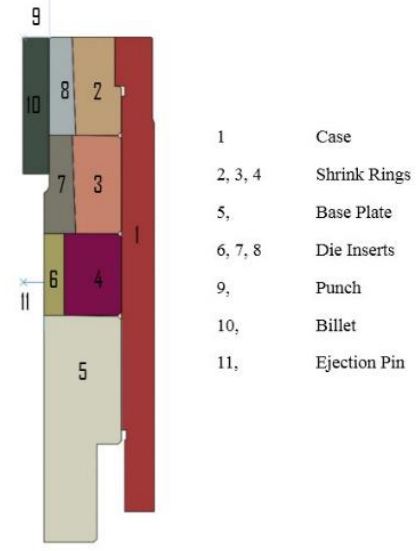

(a)

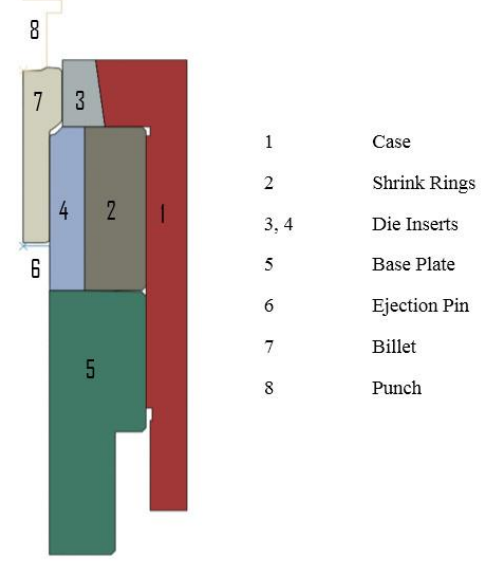

(c)

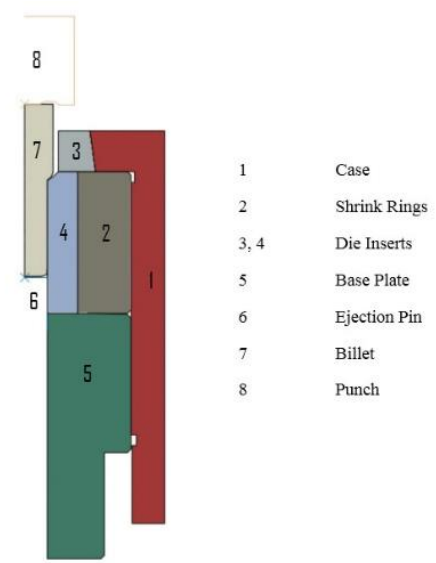

(b)

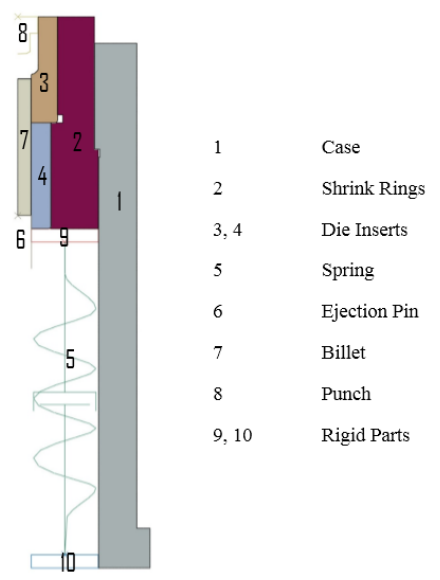

(d)

Fig. 4: Geometry model in ABAQUS: (a) first step of multisteps forging, (b) second step of multisteps forging, (c) third step of multisteps forging, (d) injection forging. 


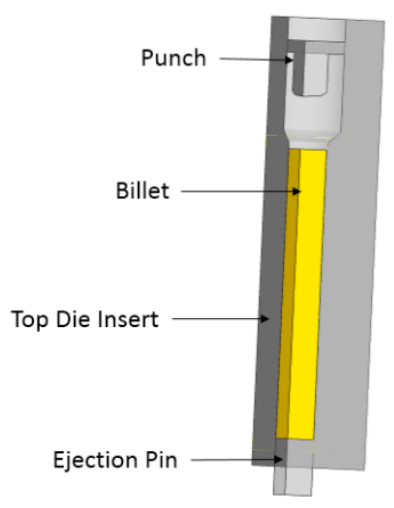

(a)

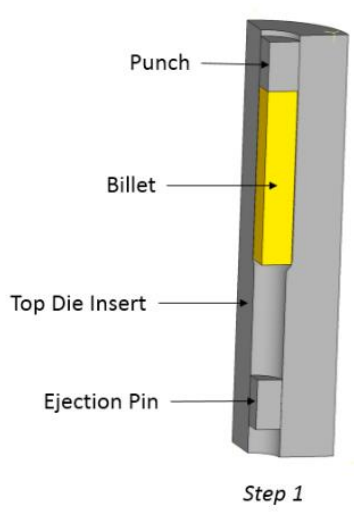

Step 1

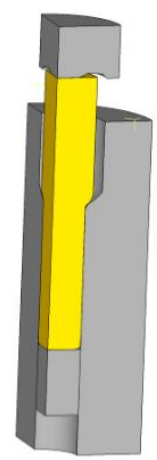

Step 2

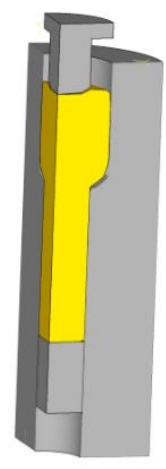

Step 3

Fig. 5: FE model in DEFORM: (a) injection forging, (b) multisteps forging.

Table 1 shows punch speed, boundary conditions and friction model used in ABAQUS and DEFORM. For both models, the punch velocity was constant and its value was decided upon by averaging the velocity used on mechanical presses in practical production (derived from around the forming of 120 pieces per minute). The coefficient of friction was determined from results of ring tests, as 0.055 .

Table 1: Boundary conditions and Friction model for ABAQUS and DEFORM.

\begin{tabular}{cccc}
\hline Software & $\begin{array}{c}\text { Punch Velocity } \\
(\mathrm{mm} / \mathrm{s})\end{array}$ & $\begin{array}{c}\text { Coefficient of } \\
\text { friction }\end{array}$ & Friction model \\
\hline ABAQUS & 45 & 0.055 & Coulomb \\
\hline DEFORM & 45 & 0.055 & Coulomb \\
\hline
\end{tabular}

AISI 1010, subjected to spheroidized annealing, was selected as the workpiece material. The stress-strain relation was stated in [18] as:

$$
\sigma=759 \varepsilon^{0.24}
$$

The material of the die inserts was tungsten carbide (WC), and other tool parts were made of AISI H13 (tool steel).

Table 2 presents the mechanical properties of these materials. 
Table 2: Material mechanical properties.

\begin{tabular}{ccccc}
\hline Material & $\begin{array}{c}\text { Density } \\
\left(\mathrm{Kg} / \mathrm{m}^{3}\right)\end{array}$ & $\begin{array}{c}\text { Young's } \\
\text { modulus } \\
(\mathrm{MPa})\end{array}$ & $\begin{array}{c}\text { Yield stress } \\
(\mathrm{MPa})\end{array}$ & Poisson's ratio \\
\hline WC [19] & $1.525 \times 10^{4}$ & 640000 & 6000 & 0.22 \\
\hline AISI H13 [20] & $7.69 \times 10^{3}$ & 212000 & 1300 & 0.3 \\
\hline AISI 1010 [20] & $7.87 \times 10^{3}$ & 205000 & 305 & 0.29 \\
\hline
\end{tabular}

Because there were three forging stages in the multisteps forging, accurate transfer of workpiece properties from step to step was important for simulation accuracy. ABAQUS provides a function called "predefined field" which introduces the data from the previous model to the next model as an initial condition. In addition, it was used to define pre-stressing in tools in ABAQUS/Explicit based on results from ABAQUS/Standard. The process of transferring in ABAQUS is shown in Fig. 6. In DEFORM, the data transfer was effected by the software automatically.

In this study, focus was on the die inserts which are core parts of the forging tools. Important stresses, axial stress S22, hoop stress S33 and mean stress, were compared to evaluate stress intensity. To make the tool stress computation more accurate, a "submodel" was used in the simulations. "Submodelling" involves the use of a global model and a submodel or multisubmodels.

In comparing component accuracy, the forging process was divided into two phases as follows:

- At the end of loading, with the component still constrained by tools. Therefore, radial tool stress influences component dimensions

- After ejection, when component stresses are relaxed and final component dimensions ae realised. .

Component accuracy was analysed on 2D profiles. The dimensional errors, $\boldsymbol{e}_{\boldsymbol{d}}$, (refer to Fig. 7) represent the forging accuracy for the forging processes. The analysis of the dimensional 
errors was concentrated on the radial dimensions of the components: the bolt head diameter $\boldsymbol{D}$ and shank diameter $\boldsymbol{d}$.
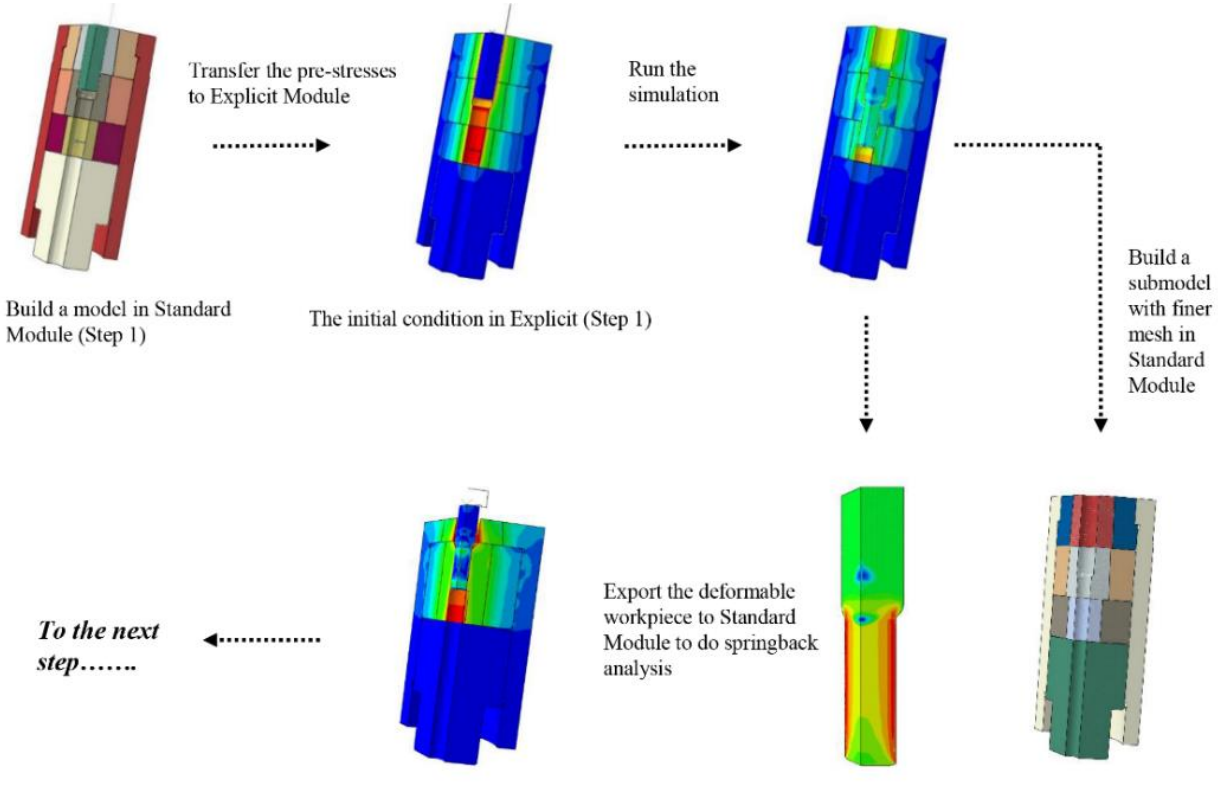

The initial condition in Explicit (Step 2)
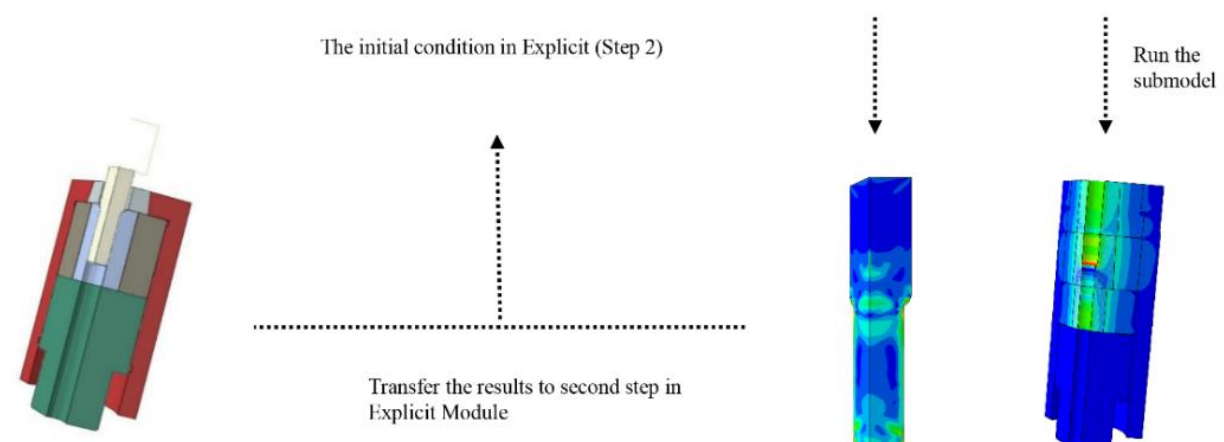

Build a model in Standard Module (Step 2)

Fig. 6: Schematic illustration of the simulation process used in ABAQUS. 

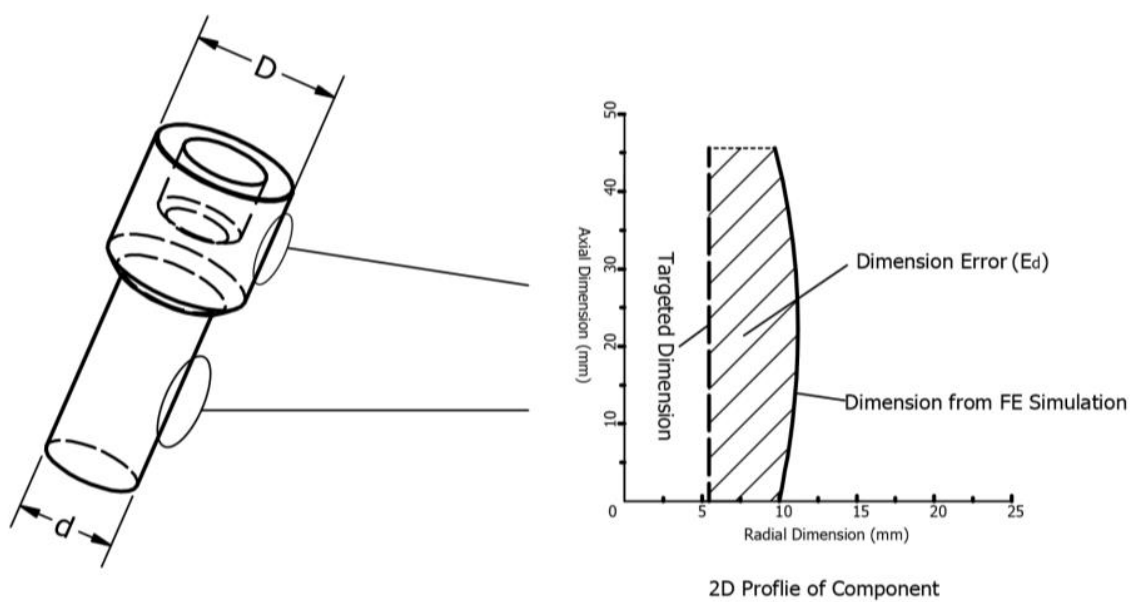

Fig. 7: Two critical parameters, $\mathrm{D}$ and $\mathrm{d}$, for forging accuracy and the dimensional errors $\mathrm{e}_{\mathrm{d}}$.

\subsection{Equipment and experimental procedure}

In the forging experiment, a 3,000 kN vertical hydraulic press was used, as shown in in Fig. 8 (a). The experimental set up consisted of three main parts; the force measurement device, and top and bottom dies (refer to Fig. 8 (b)). The forging force was measured by a load cell (Kistler 9107A) with a $700 \mathrm{kN}$ measurement range. The measuring signal, via amplifier (Kistler 5073A111) and PCI acquisition card, was recorded by a PC.

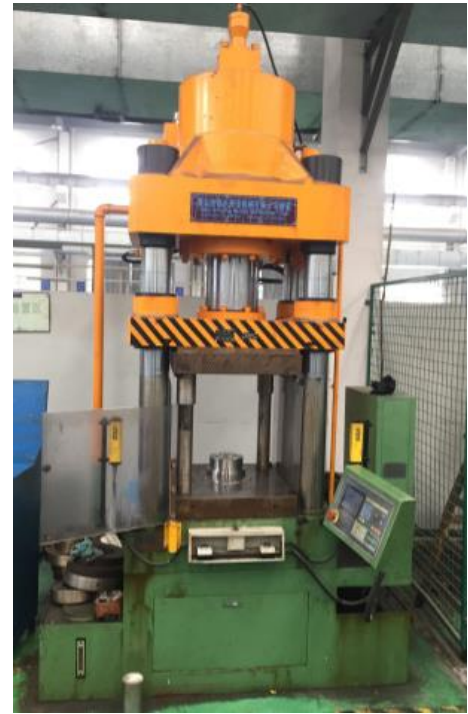

(a)

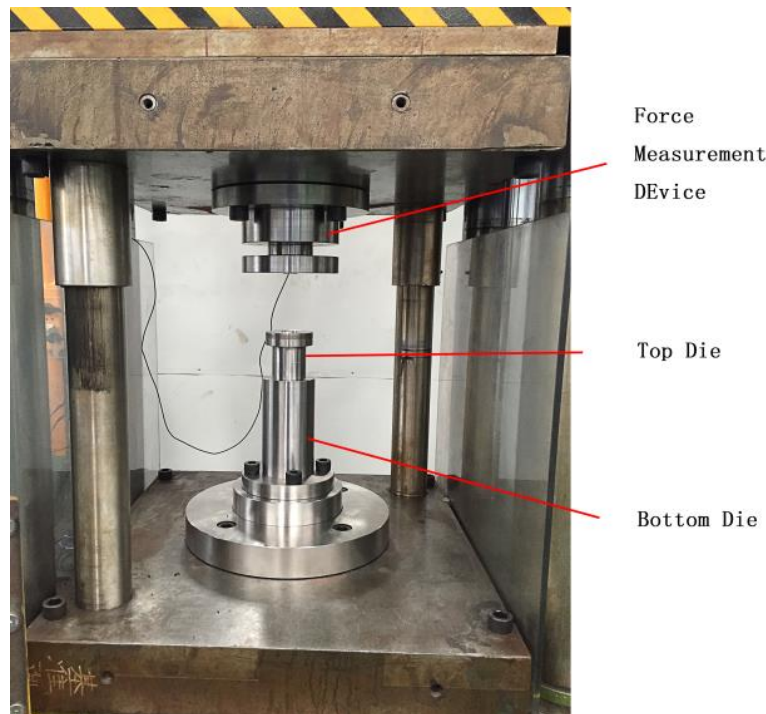

(b)

Fig. 8: Forming press and tools, (a) $3000 \mathrm{kN}$ vertical hydraulic press, (b) the experimental setup.

Specimens were cut from a phosphated and annealed AISI 1010 coil. Before the forming process, the billets and tools were measured dimensionally. They were then washed with alcohol and dried by a blow gun. Injection forging was performed in four steps, as shown in 
Fig. 9 (a). The billet, coated uniformly with lubricant (ISO100 forging oil), was placed into the bottom die-chamber. The top-die and bottom-die were then brought together: by applying a force from the machine-ram, the top-die pushed the bottom-die insert down which deformed the billet. When the stroke was achieved with the set value, the machine-ram returned to its original position. At the same time, the spring forced the bottom-die insert back to its initial position. The ejection pin then knocked the workpiece out from the die chamber.

After forging, two post-measurements were conducted on the components, including a hardness test and a grain flow analysis. Fig. 9 (b) shows the specimen for the micro-hardness test. Because the component was symmetrical, this test was only conducted on half of the specimen based on the centre line, seen in Fig. 9 (c). The measurement process referred to ASTM E3-11 2011 [21]. For the grain flow line analysis, it was conducted mainly on the head of bolt which is the most critical part of the fastener. The process is done accordingly to ASTM E381-01 [22].

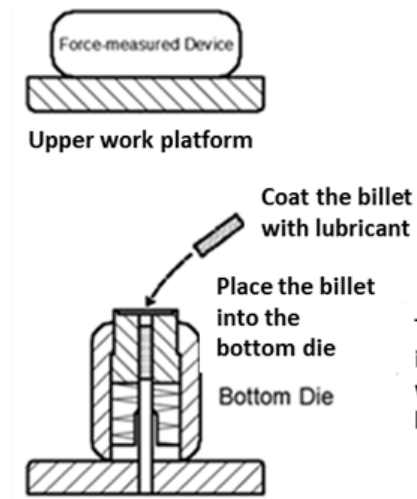

Bottom work platform
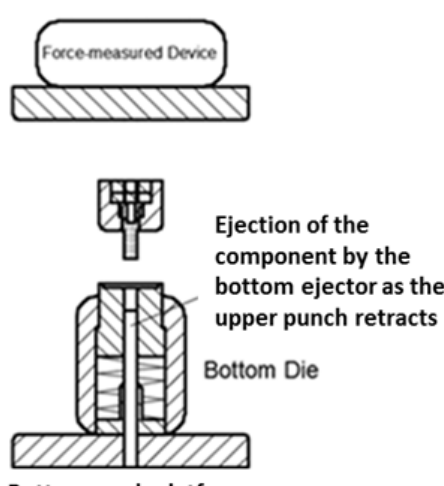

Bottom work platform

3
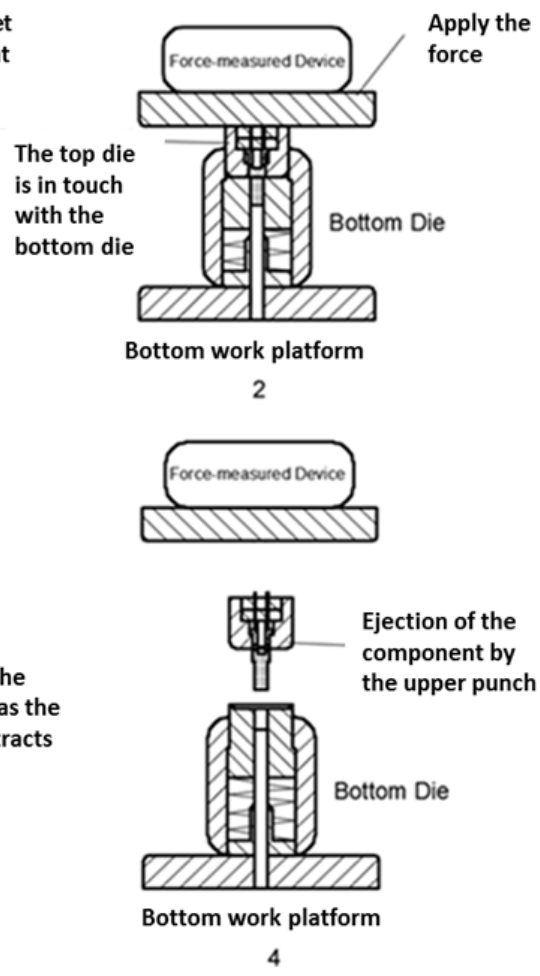

(a)

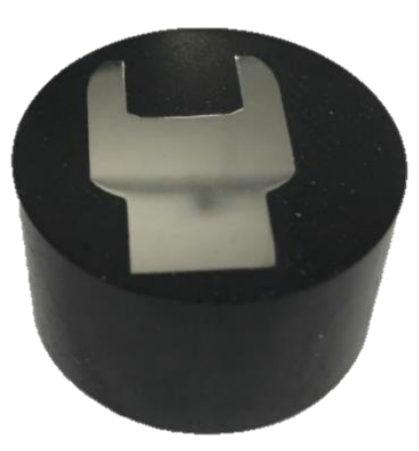

(b)

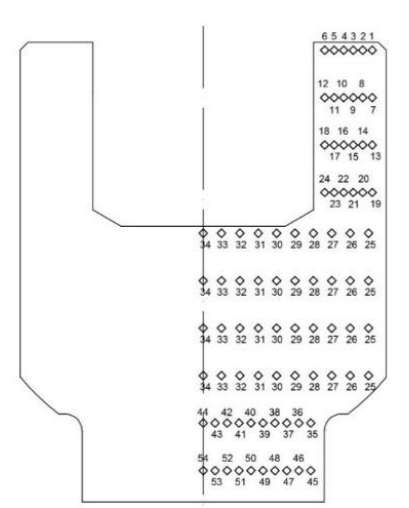

(c) 
Fig. 9: The illustration of injection forging process and hardness test, (a) forging process, (b) mounted specimen for hardness test, and (c) indenting positions

\section{Results and Discussion}

\subsection{Comparison of injection forging and multisteps forging}

\subsubsection{Forging force}

Fig. 10 shows the forging force prediction from ABAQUS and DEFORM. The effective stress distribution in the workpiece was showed in Fig. 10 either. Compared with multisteps forging, injection forging, as one step forging, requires a higher final force. This will cause higher stresses and deflections in the tools, resulting in a potential issue of forming accuracy. Besides a higher load requirement, the rate of force increase changes more frequently in injection forging than that in the multisteps forging. This could adversely influence the lifespan of tools, and it could be an issue for injection forging in high volume production. Injection forging requires less deformation energy that that of multisteps forging. When considering some associated energy expended in production, e.g. transferring the workpiece between forging stages, this advantage becomes more obvious. In this respect, it appears that injection forging can help industry to reduce the cost of forging.

Table 3: Comparison of forging force and forging energy for multisteps forging and injection forging.

\begin{tabular}{|c|c|c|c|c|}
\hline Process & $\begin{array}{c}\text { Multisteps } \\
\text { forging } \\
\text { (stage 1) }\end{array}$ & $\begin{array}{c}\text { Multisteps } \\
\text { forging } \\
\text { (stage 2) }\end{array}$ & $\begin{array}{c}\text { Multisteps } \\
\text { forging } \\
\text { (stage 3) }\end{array}$ & $\begin{array}{l}\text { Injection } \\
\text { forging }\end{array}$ \\
\hline $\begin{array}{l}\text { ABAQUS predicted Max. Force } \\
\qquad(\mathrm{kN})\end{array}$ & 205.322 & 231.754 & 185.837 & 240.346 \\
\hline $\begin{array}{l}\text { DEFORM predicted Max. Force } \\
\qquad(\mathrm{kN})\end{array}$ & 207.916 & 229.920 & 182.928 & 270.864 \\
\hline \multirow{2}{*}{ Forging Energy $(\mathrm{kJ})$} & 1290 & 517 & 748 & \multirow{2}{*}{2280} \\
\hline & \multicolumn{3}{|c|}{ Total Energy $=2555$} & \\
\hline Extra Stroke (mm) & 0.440 & 0.255 & - & 0.515 \\
\hline
\end{tabular}




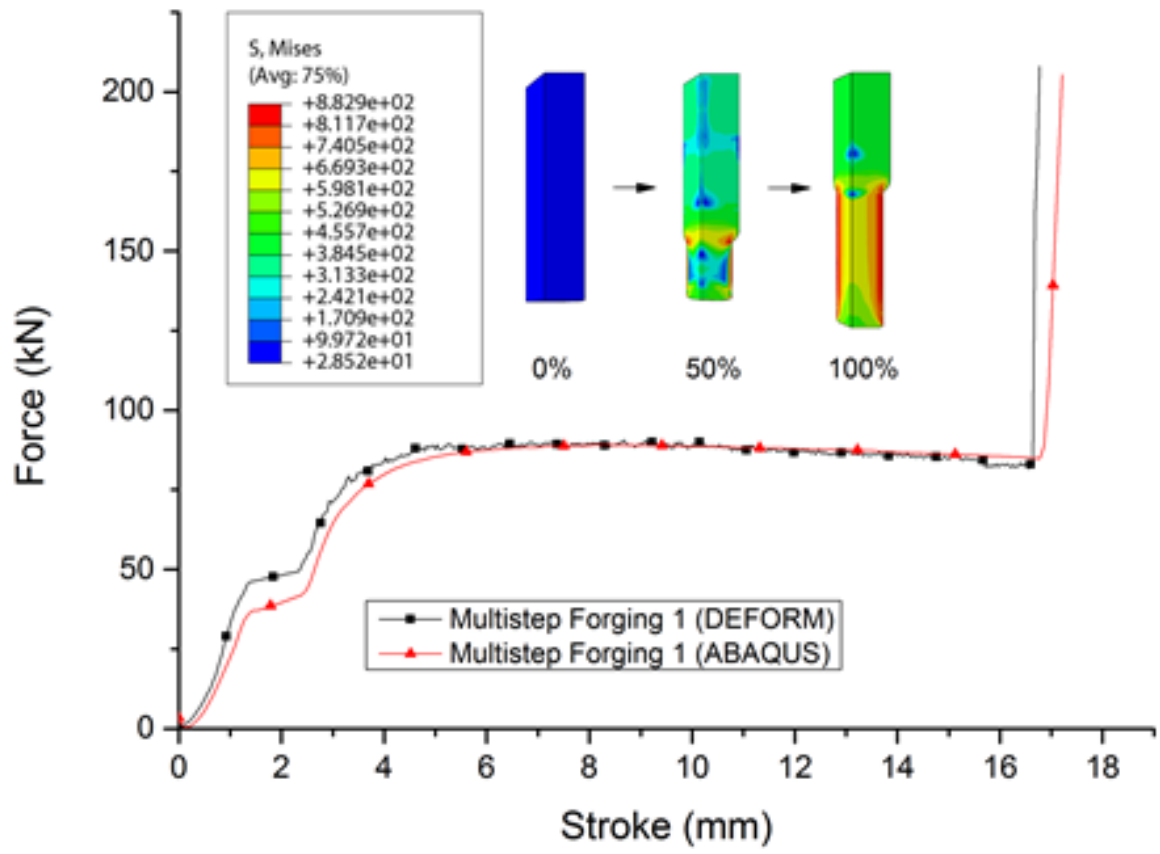

(a) Step 1

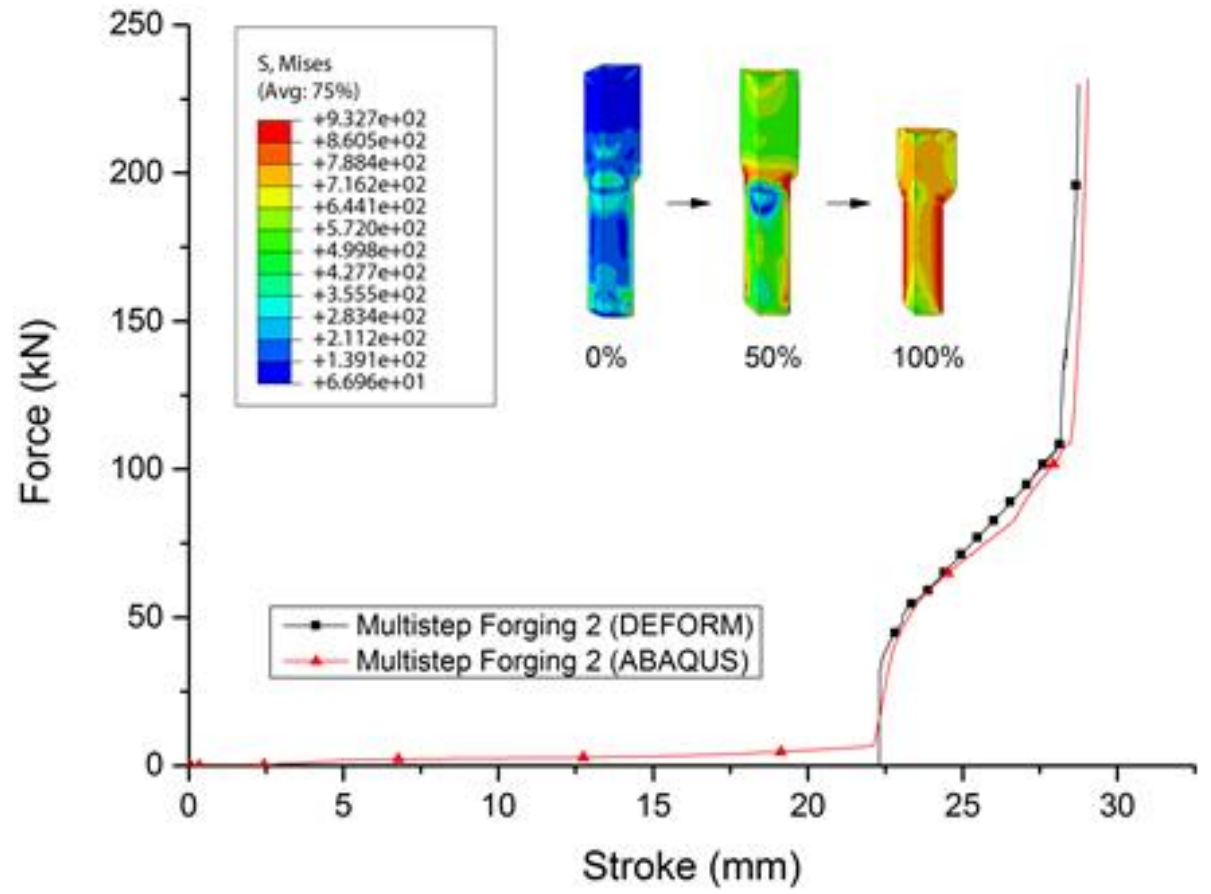

(b) Step 2 


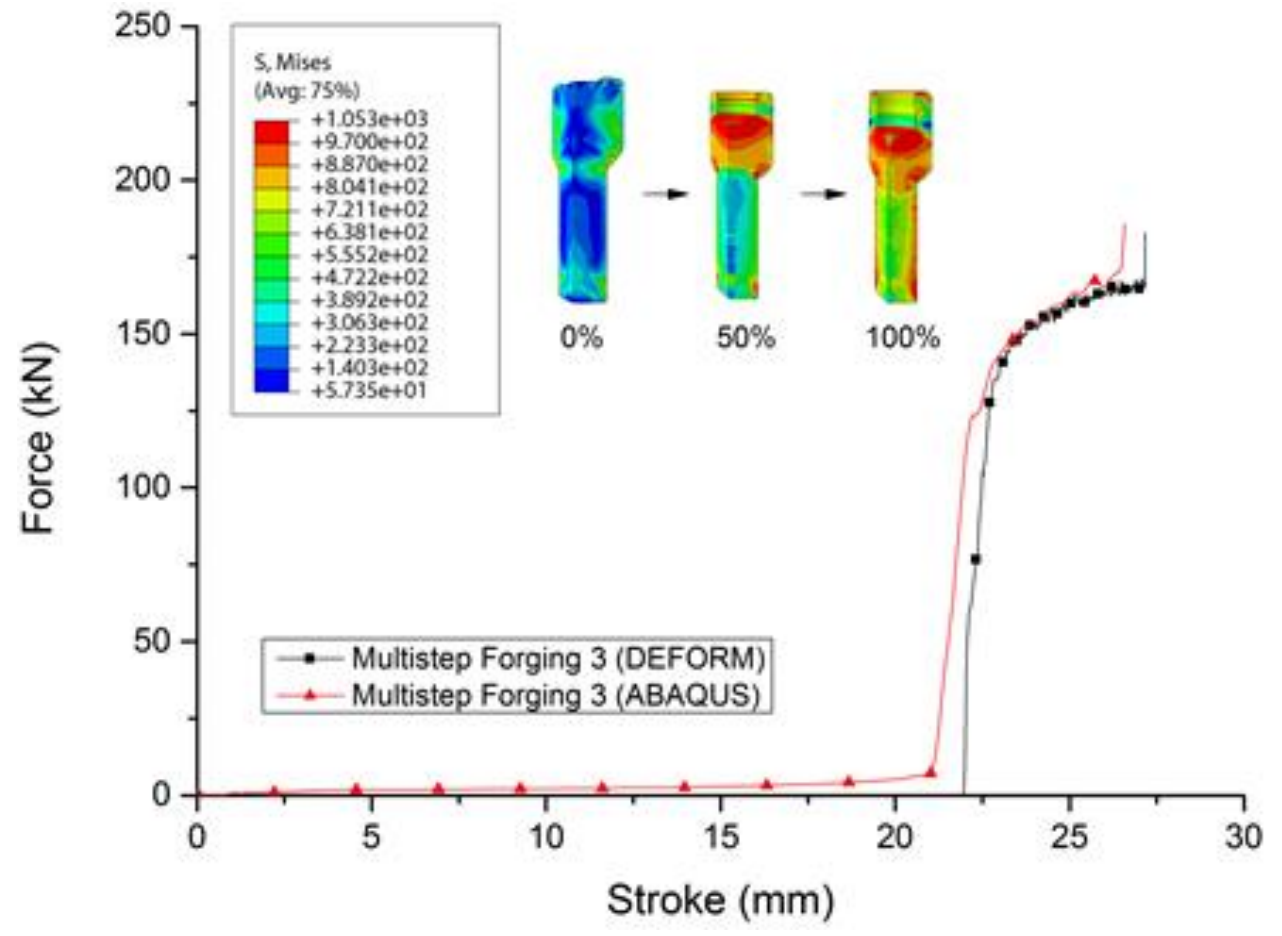

(c) Step 3

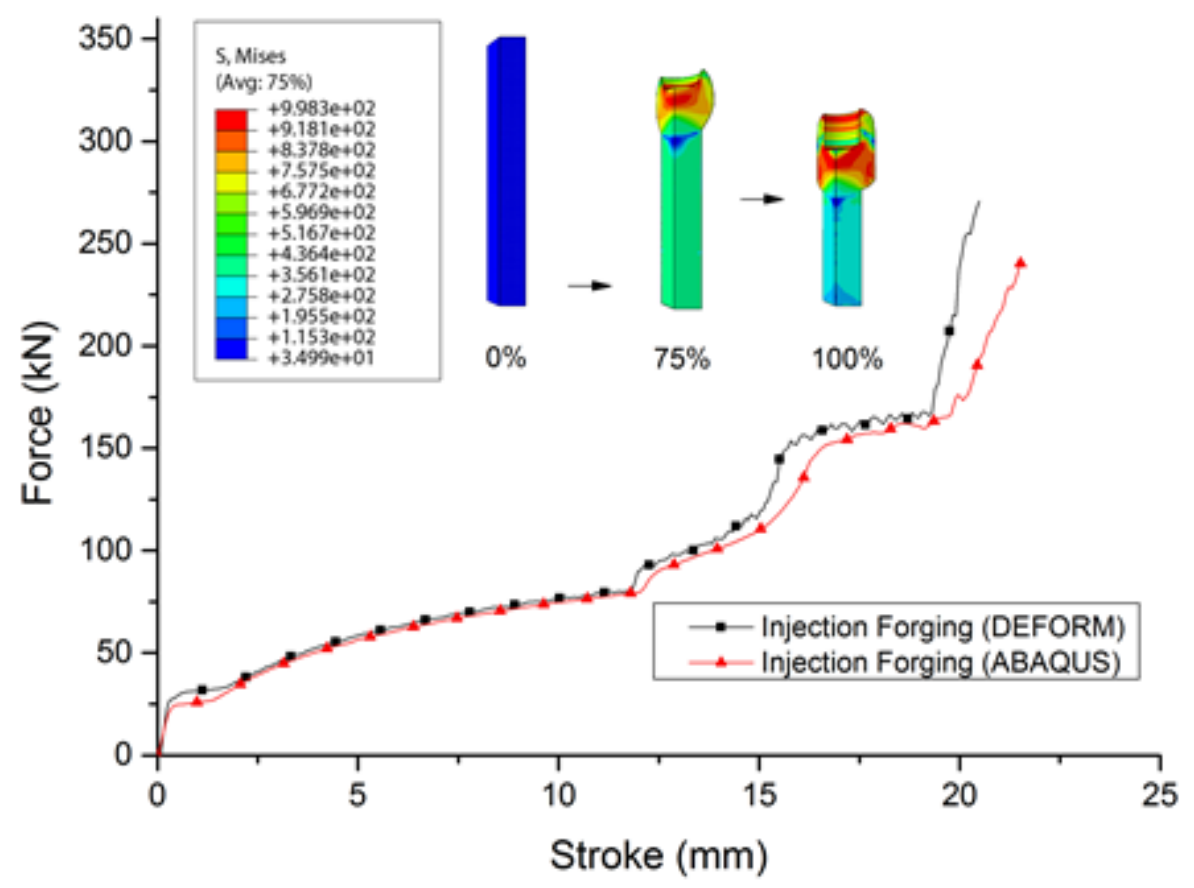

(d) Injection forging

Fig. 10: The force-stroke curve from DEFORM and ABAQUS, (a) step 1 in multisteps forging, (b) step 2 in multisteps forging, (c) step 3 in multisteps forging, (d) injection forging. 


\subsubsection{Tool stresses}

Fig. 11 to Fig. 13 show the differences in maximum stress for forging processes. Judging by the stress values, in multisteps forging, step 2 requires the maximum force. However, the maximum effective stress in step 2 is small which is close to the level of pre-stressing. It is because the upsetting in step 2 is virtually unconstrained; the main deformation is almost completed before the workpiece touches the die insert. Therefore, the die insert sustains a small forming pressure. The same situation happens in step 3. In contrast, in step 1, the workpiece contacts with the die insert at the beginning of forging. It introduces extremely high stresses to the die, especially in the second die insert. This indicates that step 1 is the most critical step in multisteps forging. Effective stress, hoop stress and axial stress are all high and in tensile states, resulting in a situation in which fatigue cracking is most likely to be initiated.

Compared with multisteps forging, the die insert (refer to the Fig. 4 for the tool configurations) experiences the highest effective stress in injection forging, and the position of the stress concentration is different. The stress is focused only on the bottom part of the die insert. This is because of the different material flow characteristics. In injection forging, the material in the bottom part of the workpiece does not deform significantly in the axial direction. Only a small amount of radial flow takes place in this area and after the workpiece contacts the die insert, the "dead-zone" material has no space in which to flow. An increasing force leads to greatly increasing stresses in the trapped work-piece. Besides the effective stress, the positive hoop stress and axial stress also reflect potential issues about tool life in injection forging. Because pre-stressing has a significant influence on the stress-state in the die-set, it suggests that the die-set for injection forging would require higher pre-stressing. 


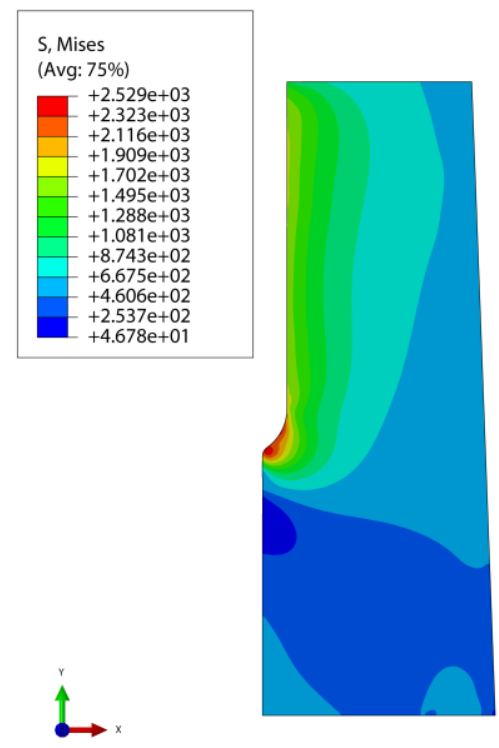

(a)

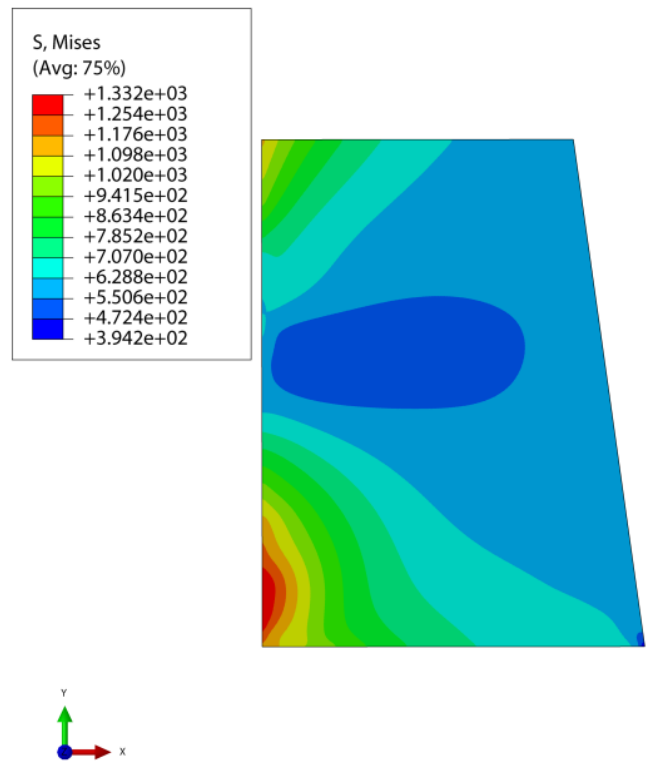

(c)

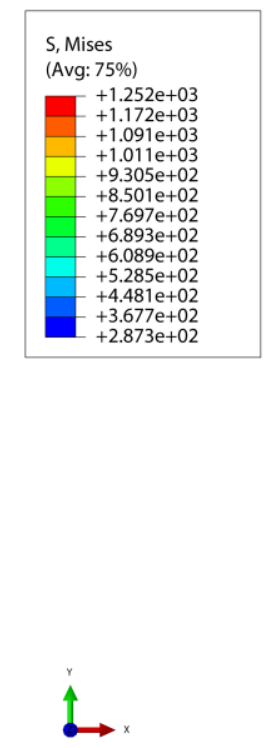

(b)

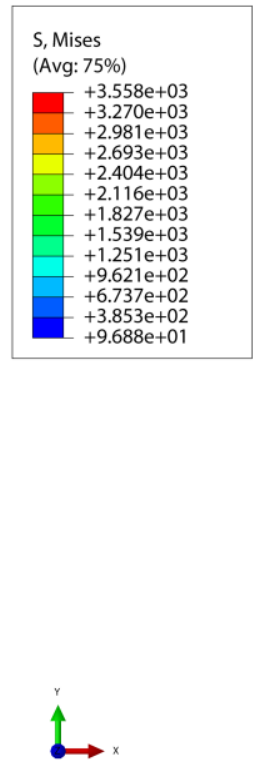

(d)

Fig. 11: Effective stress distribution in die inserts: multisteps: (a) step 1, (b) step 2, (c) step 3, and (d) injection forging. 


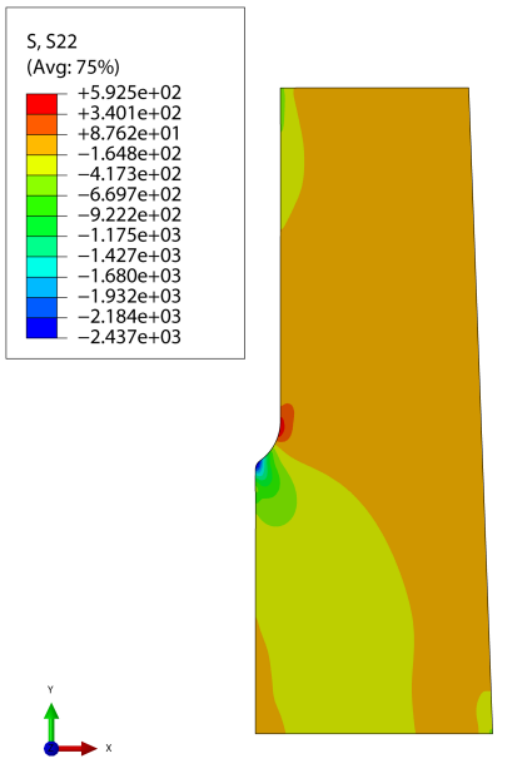

(a)

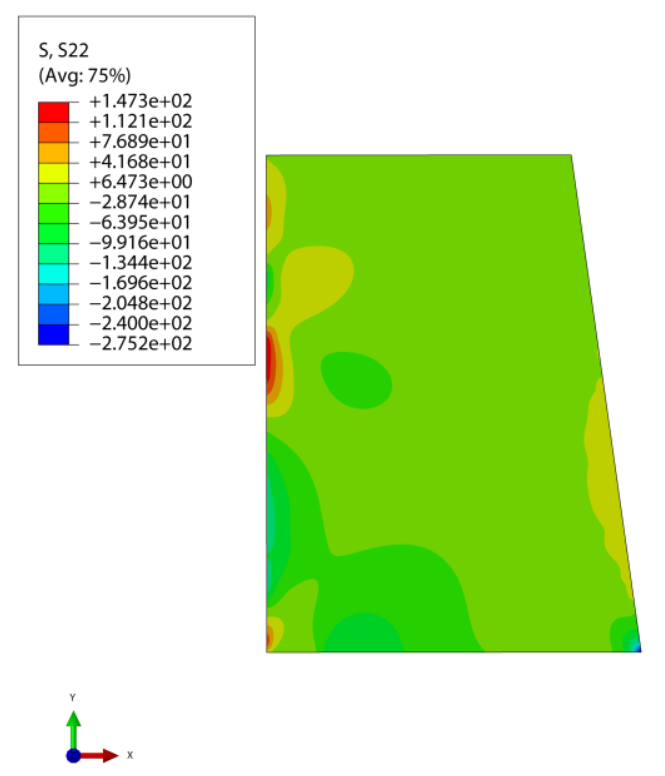

(c)

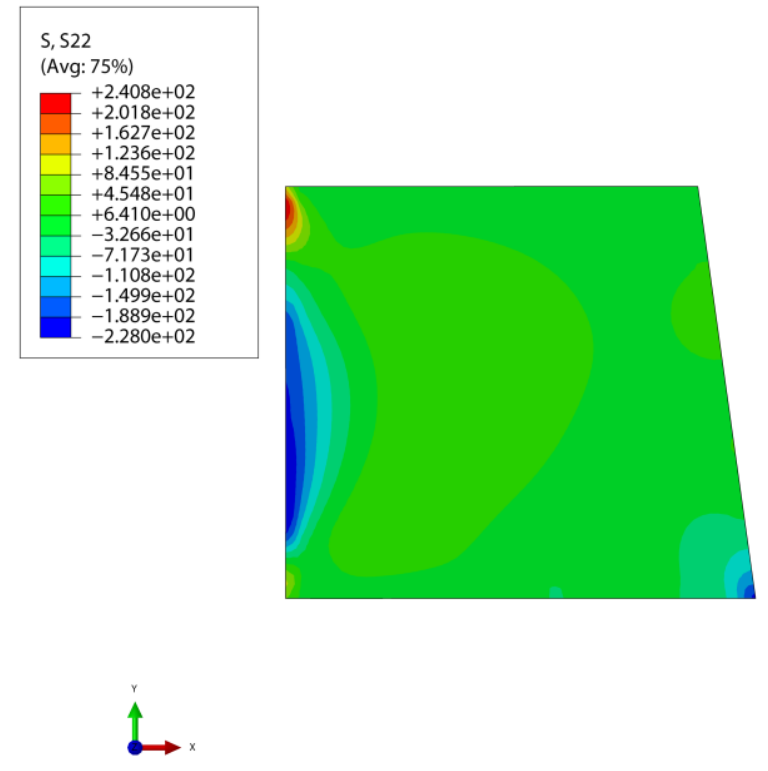

(b)

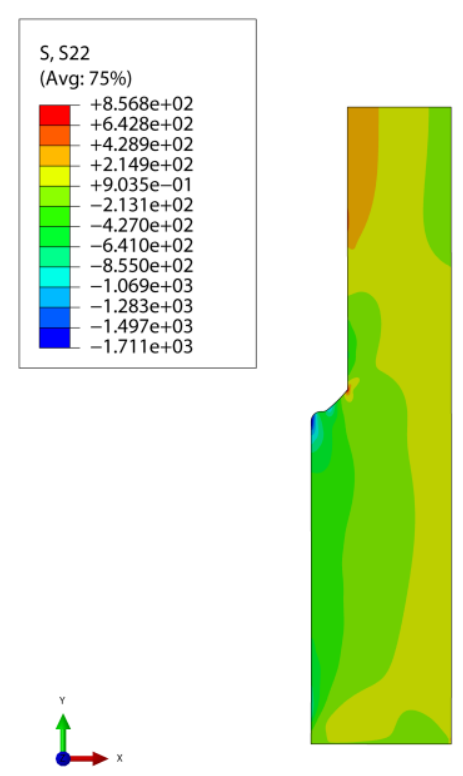

(d)

Fig. 12: Maximum axial stress distribution in die inserts: Multisteps: (a) step 1, (b) step 2, (c) step 3, and (d) injection forging. 


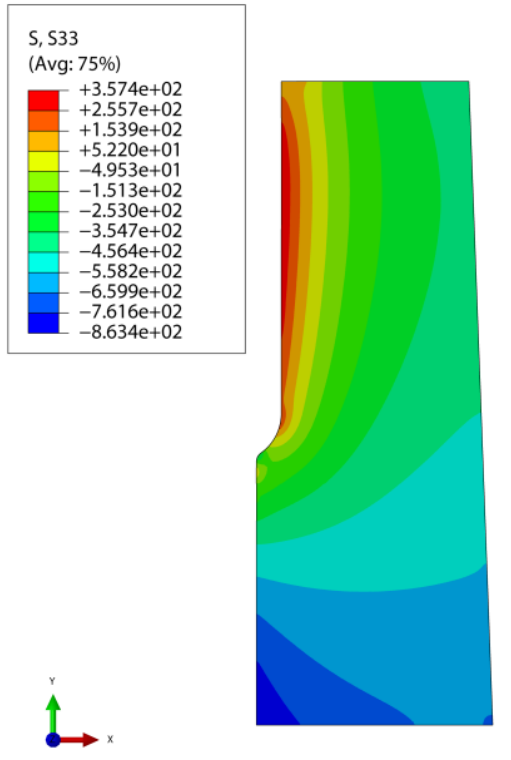

(a)

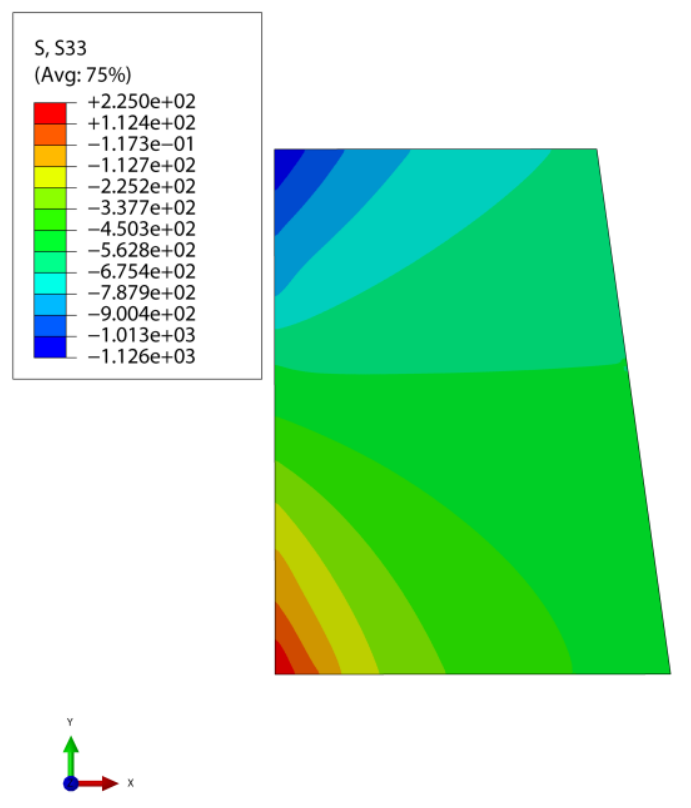

(c)
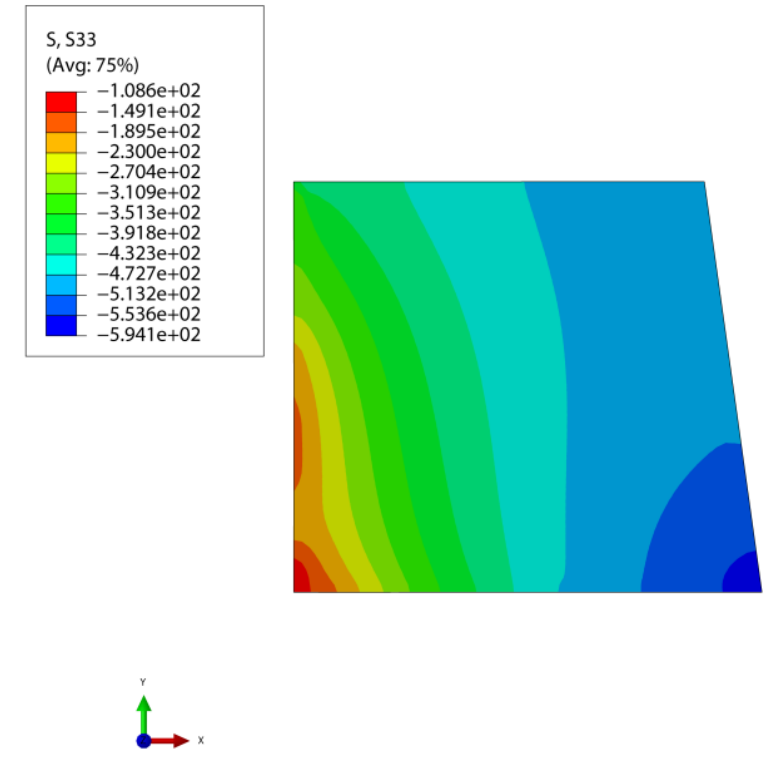

(b)

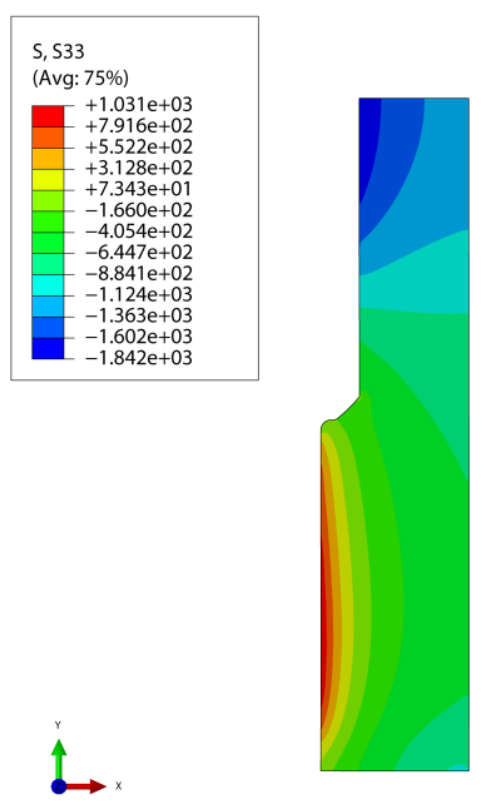

(d)

Fig. 13: Maximum hoop stress distribution in die inserts: multisteps: (a) step 1, (b) step 2, (c) step 3, and (d) injection forging. 


\subsubsection{Comparison of the forming accuracy}

The component dimensions for sections $\mathrm{D}$ and $\mathrm{d}$ for multisteps forgings are presented in Fig. 14, Fig. 15 and Fig. 16. The same dimensions are presented for injection forging, in Fig. 17. Some potential positions for folding are highlighted in these figures.

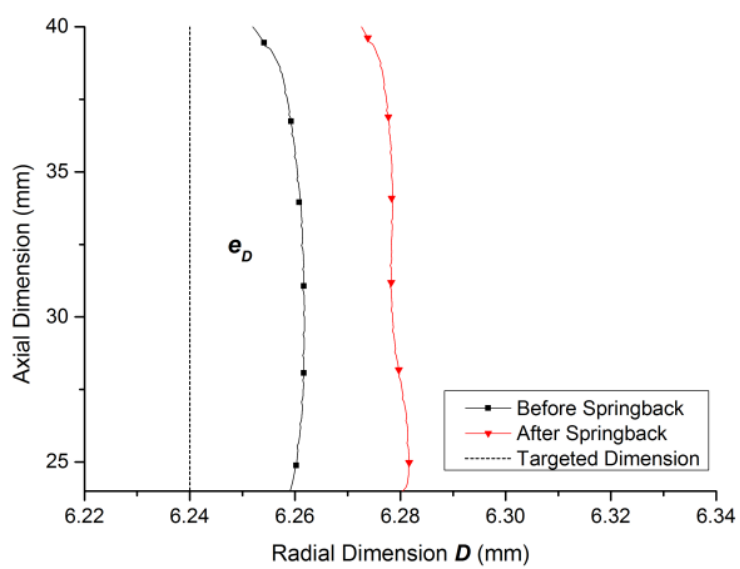

(a)

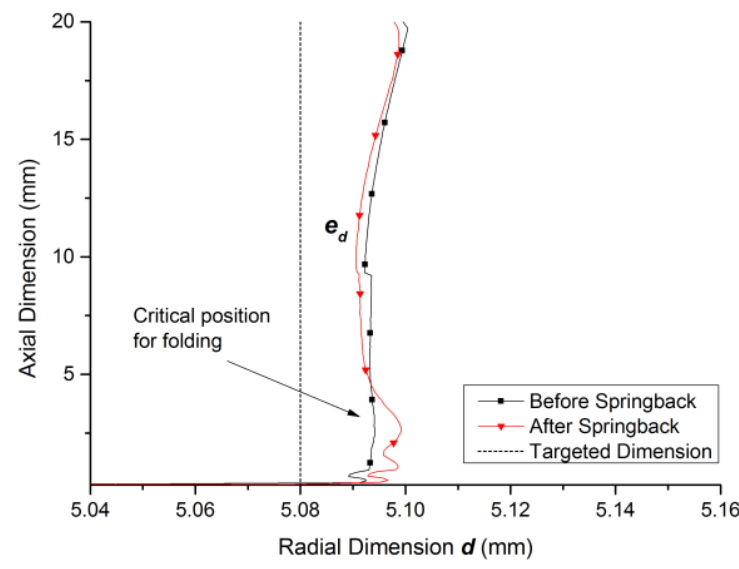

(b)

Fig. 14: 2D profile before and after springback in multisteps forging step 1, (a) section D, and (b) section d.

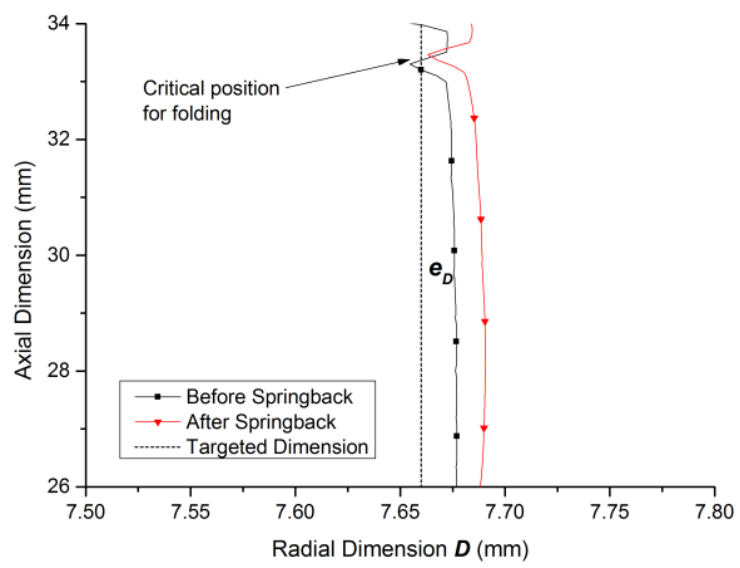

(a)

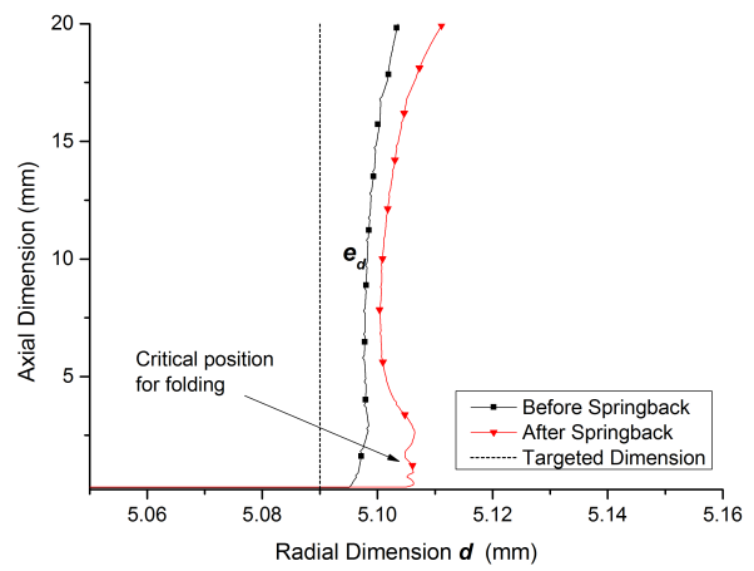

(b)

Fig. 15: 2D profile before and after springback in multisteps forging step 2, (a) section D, and (b) section d. 


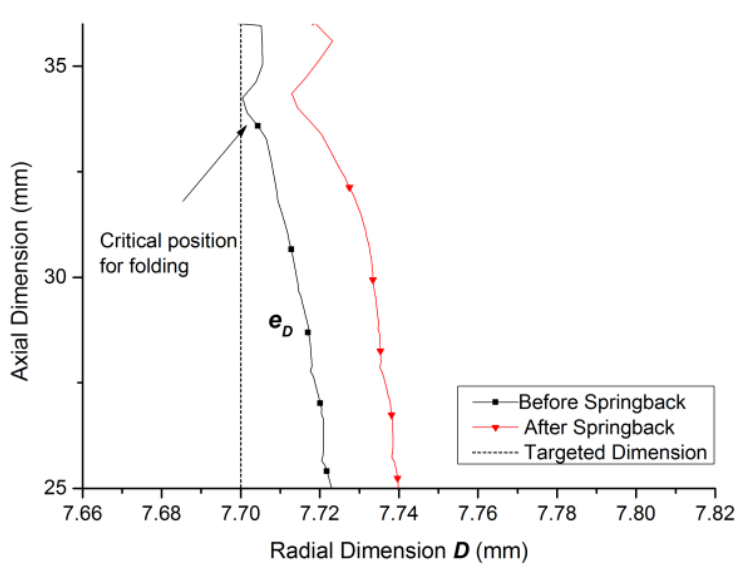

(a)

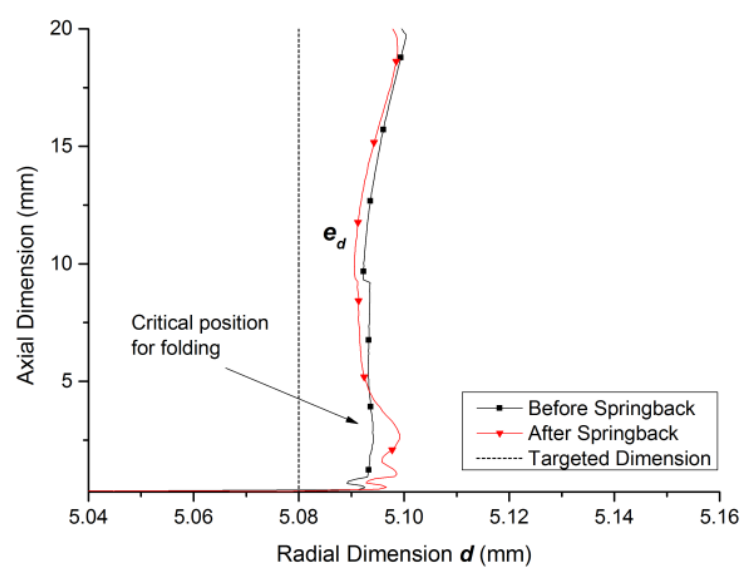

(b)

Fig. 16: 2D profile before and after springback in multisteps forging step 3, (a) section D, and (b) section d.

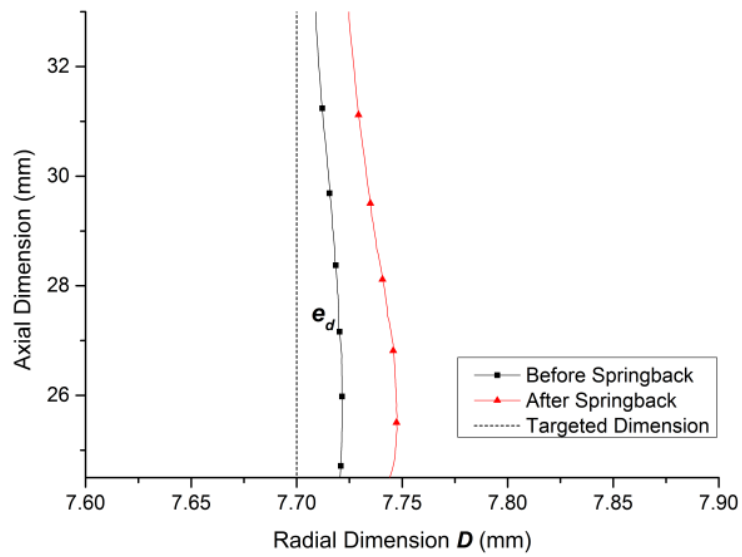

(a)

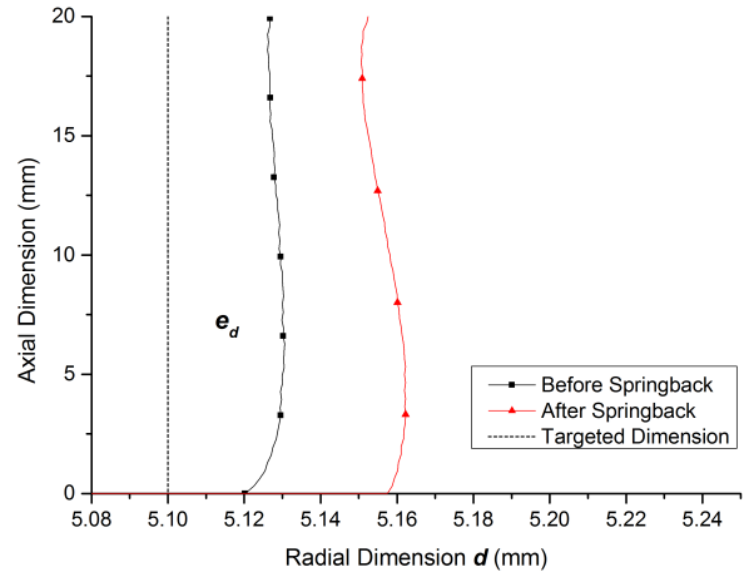

(b)

Fig. 17: 2D profile before and after springback in injection forging, (a) section $D$, and (b) section $\mathrm{d}$.

As can be seen from these figures, the final dimensions of sections $\boldsymbol{d}$ and $\boldsymbol{D}$ exceed the targeted value for both multisteps forging and injection forging. Based on the magnitude of errors, Table 4 is employed to evaluate forming accuracy. There are two main reasons for dimensional errors in the simulation. One is tool deflection, and another is springback of the workpiece. The amplitude of tool deflection is reflected by the component dimensions before springback. The largest tool deflection happens in injection forging which creates around $0.028 \mathrm{~mm}$ dimensional error in section $\boldsymbol{d}$. Due to the deformation being finished in one step for injection forging, high finishing tool stresses and hence large tool deflection, cannot be avoided. For the multisteps forging, the degree of tool deflection reduces step by step. 
When a part is released from the tools springback contributes to an increased dimensional error. For injection forging, the mean errors increase to about twice those before springback. However, in multisteps forging (step 1), the $\overline{\boldsymbol{e}}_{\boldsymbol{d}}$ drops slightly from $0.014 \mathrm{~mm}$ to $0.013 \mathrm{~mm}$. This is caused by the die insert design. Referring to Fig. 18, in order to reduce the friction force, a die land $\boldsymbol{L}$ is employed at the exit of extrusion. When the workpiece has passed thorugh the land it is no longer constrained by the tool and relaxes and becomes stress free.
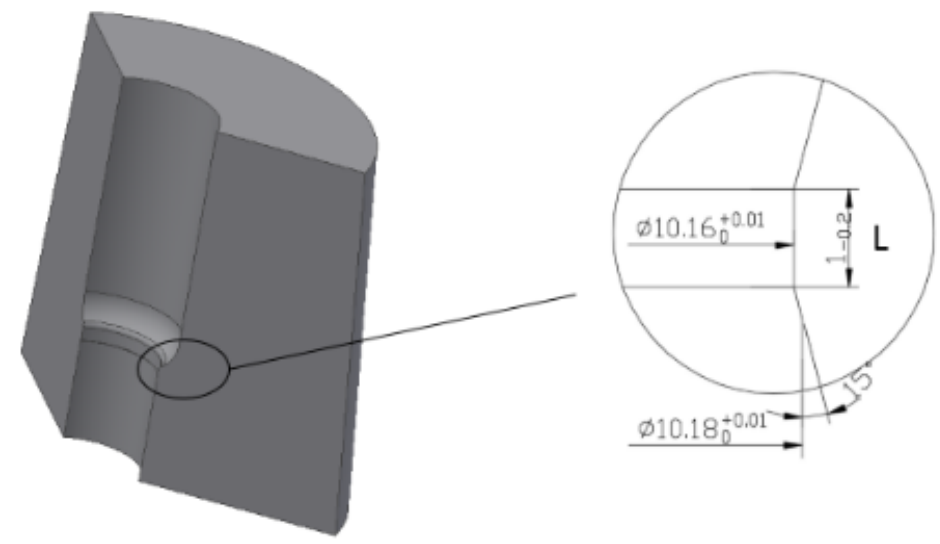

Fig. 18: Die-insert design in forging step 1 in multisteps forging (refer to Fig. 4(a) for the whole tooling, and the die-insert is Part No. 7).

On the other hand, due to the different degrees of springback the underlying folding risk for the subsequent forging process increased, this being shown in the figures from Fig. 14 to Fig. 16. A typical example is presented in step 1 in which the bottom dimension in section $\boldsymbol{d}$ has a big change after springback. In addition to springback, some critical dimensions grow inprocess, e.g. the critical part in section $\boldsymbol{D}$ of step 2 (in the figure 15 (a) which is pointed by an arrow). This suggests that some optimisation should be conducted in step 2 to prevent this risk. Although the multisteps processes have been used in industry to make millions of parts successfully, applying such a process for the forging of the wheel bolt examined in this study does need careful process and tool design to avoid the problem mentioned here. Nevertheless, it is noticeable that such problems would not be obvious for injection forging in section $\boldsymbol{D}$ and $\boldsymbol{d}$. 
Table 4: Comparison of the component accuracy for multisteps forging and injection forging.

\begin{tabular}{cccccc}
\hline & Process & $\begin{array}{c}\text { Multisteps } \\
\text { forging } \\
\text { (step 1) }\end{array}$ & $\begin{array}{c}\text { Multisteps } \\
\text { forging } \\
\text { (step 2) }\end{array}$ & $\begin{array}{c}\text { Multisteps } \\
\text { forging } \\
\text { (step 3) }\end{array}$ & $\begin{array}{c}\text { Injection } \\
\text { forging }\end{array}$ \\
\hline $\begin{array}{c}\text { Mean } \\
\text { Error } \bar{e}_{D} \\
(\mathrm{~mm})\end{array}$ & Before Springback & 0.020 & 0.014 & 0.014 & 0.017 \\
\cline { 2 - 6 } & After Springback & 0.039 & 0.027 & 0.032 & 0.038 \\
\hline $\begin{array}{c}\text { Mean } \\
\text { Error } \bar{e}_{d} \\
(\mathrm{~mm})\end{array}$ & Before Springback & 0.014 & 0.009 & 0.006 & 0.028 \\
\cline { 2 - 6 } & After Springback & 0.013 & 0.013 & 0.006 & 0.057 \\
\hline
\end{tabular}

\subsubsection{Grain Flow Lines}

Fig. 19 shows the prediction of grain flow in the two processes. In service, the bolt mainly resists the force in two directions. One is in the axial direction which is tensile stress, and another is shear stress in the horizontal direction. According to the results, the components from injection forging and multisteps forging show the same flow lines in the shank. Therefore, the mechanical behaviour in the rod part for the two processes is likely to be similar. Considering the head part of the bolt, the component from multisteps forging exhibits better behaviour. The relative mild flow line helps the bolt to resist both stresses. Meanwhile, due to the metal flow in injection forging, the flow line in position $\mathrm{A}$ of the component is horizontal (refer to Fig. 19 (b)). Therefore, this may suggest that A may be a critical position where breaking may occur if high tensile stress exists in this section, e.g. large force applied by a spanner, although the bolt may not be stressed in this region under service conditions.
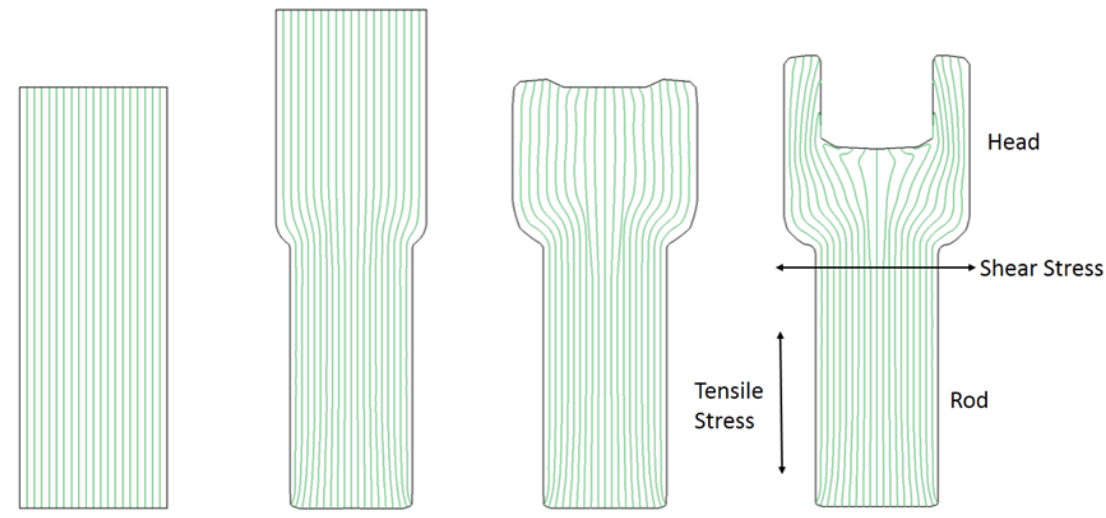

(a) 

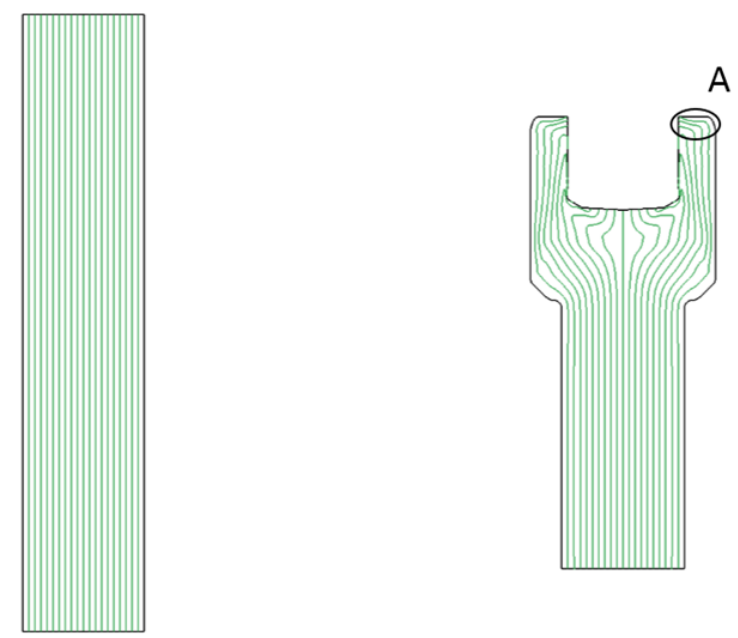

(b)

Fig. 19: Grain flow line prediction: (a) multisteps forging, (b) injection forging.

\subsection{Injection Forging Experimental Validation}

\subsubsection{Forging force}

Fig. 20 shows the experimental forging force in comparison with the simulation results. It indicates a good agreement in force growth tendency. However, in view of force magnitude, the estimated value of simulation is slightly higherer. With ABAQUS, the maximum force predicted is around $240 \mathrm{kN}$ which exceeds by around $18 \%$ of the experimental results. This may be caused by the material model used in FE modelling as well as the meshing scheme used and definition of the boundary conditions.

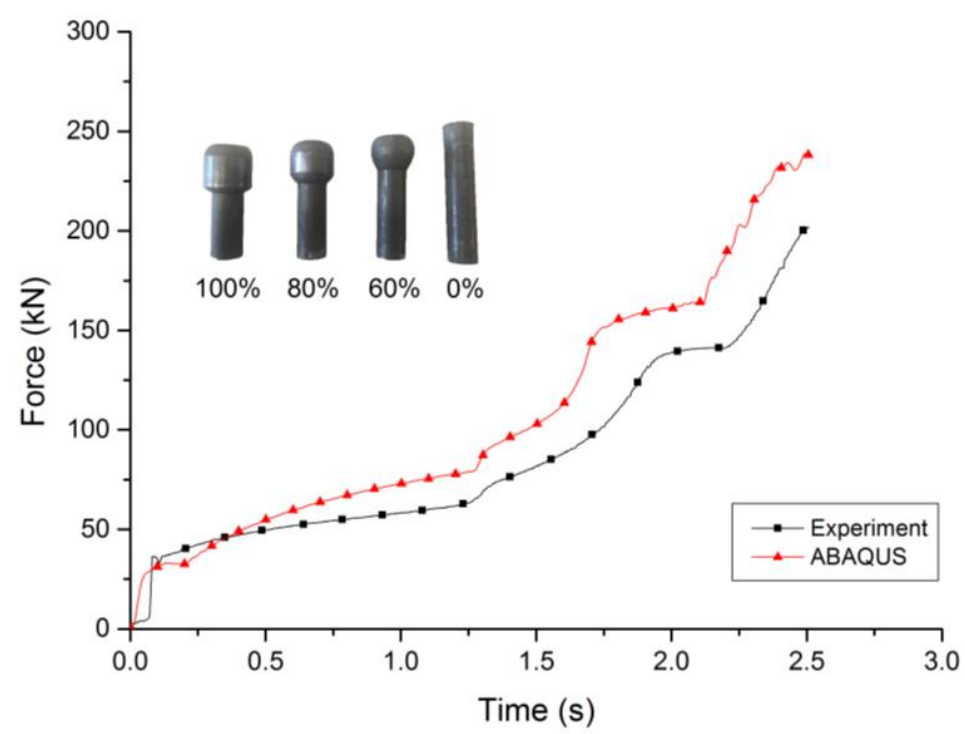

Fig. 20: Comparison of forging force between the experiment and simulation results. 


\subsubsection{Hardness}

Fig. 21 (a) shows the hardness distribution at the specimen after forging. The maximum hardness is located on region A which is caused by forming the bore. Hardness gradually reduces with distance from region $\mathrm{A}$. In the process of reduction, region $\mathrm{B} / \mathrm{C}$ remains at a relatively high level. This implies that the plastic deformation in region $\mathrm{B} / \mathrm{C}$ is severe. The minimum hardness is in the shank. It is close to the initial material hardness which is 88.5 HRB. This is because the material on the rod part, especially the material in the centre of the rod, does not participate in large plastic deformation, and and the plastic strain in this part was aout 0.025 . The rod diameter increases from $10.1 \mathrm{~mm}$ to $12.1 \mathrm{~mm}$.

According to the literature [23], a value of the effective plastic strain in the specimen may be converted to a hardness value using the following expression for AISI 1010 steel:

$$
H_{v}=102.8+84.9 \bar{\varepsilon}^{0.4}
$$

Here, $H_{v}$ is Vickers Hardness and $\bar{\varepsilon}$ effective plastic strain. Similar coversion was used in this study: Fig. 21 (b) shows the predicted hardness distribution in the specimen, based on the simulated strain values with ABAQUS. Comparing the predicted values with experimental ones (refer to Fig. 21 (a)), the distribution of the hardness is similar. The locations of the high hardnesses, e.g. points $A_{1}, B_{1}$ and $C_{1}$ from the simluation, correspond to that for high hardness points $\mathrm{A}, \mathrm{B}$ and $\mathrm{C}$ of the sample part obtained from the experiment.
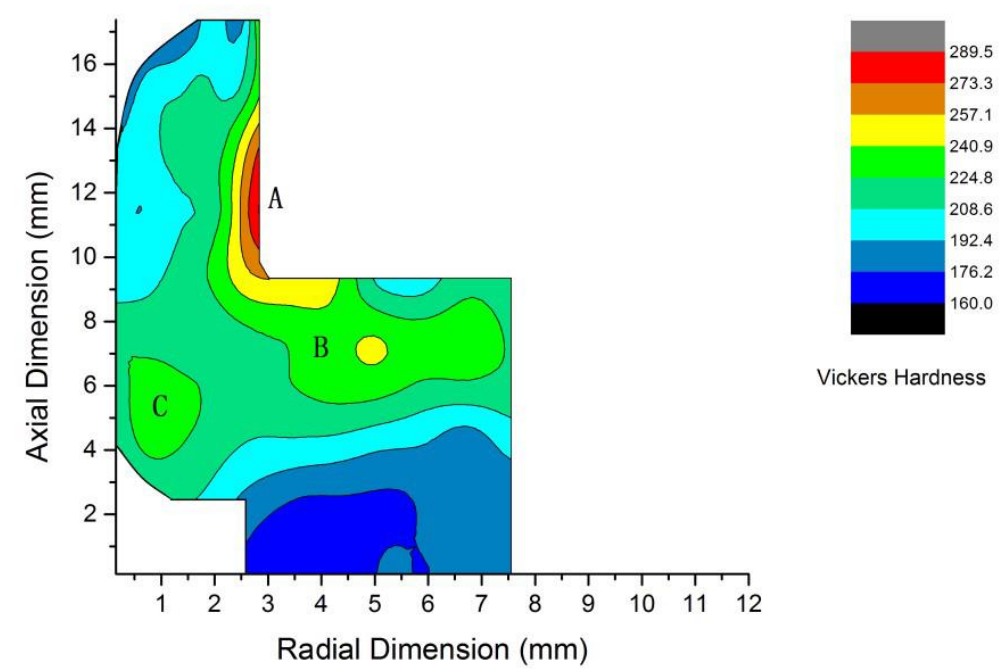

(a) 

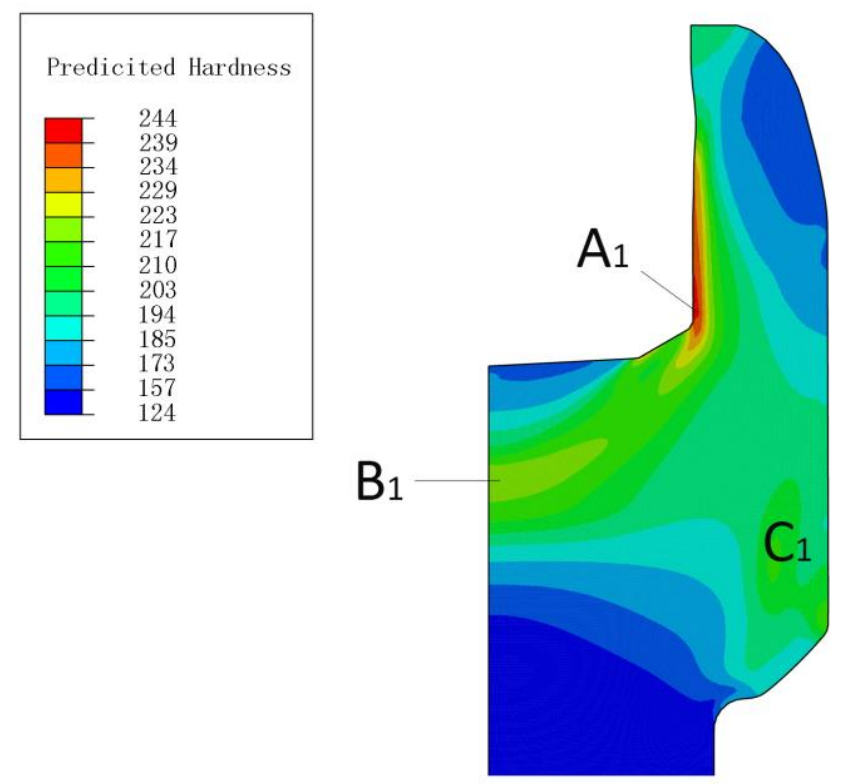

(b)

Fig. 21: (a). Contour of the hardness of the workpiece measured, (b). Predicted hardness of the workpiece based on the FE simulated strain values.

\subsubsection{The sample parts obtained from the experiment}

The sample parts forged with the injection forging tool showed similar geometric profiles and dimensions that were obtained from FE simulations. Reasonable surface quality was also obtained.

During forging, some brittle inclusions in the material are destroyed by forging. These inclusions display a flow line along the component forming direction after macro etching. In this test, the grain flow line of AISI 1010 is not very obvious, and only the flow line in the centre of the specimen is visible in

Fig. 22. Compared with the simulation results, the grain flow lines of the sample parts obtained from the experiments are generally similar to what obtained from the FE simulations, although these are not fully symmetrical. This may be caused by several factors, such as uneven end-surface of the initial specimen, boundary conditions, and the symmetry of material's micro-structures across the section. On the other hand, the tool assembly and stiffness and the placement of workpiece not exactly in the centre are also possible reasons for the uneven grain flow observed. 

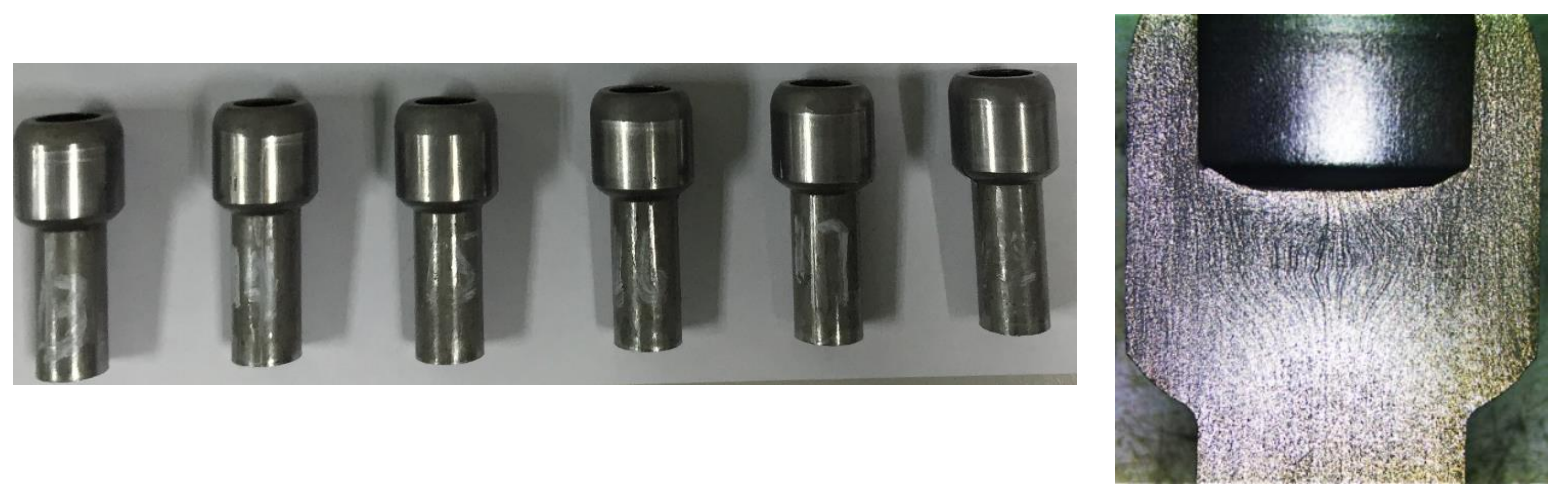

Fig. 22: Sample parts formed and grain flow line of a part under a microscope

\section{Conclusions and Recommendations}

From the work carried out in FE simulations, forging experiment and sample parts analysis the following conclusions may be drawn:

[1]. A new forging method for reducing process steps in automotive fasteners production has been proposed; FE simulation and forging experiment results confirmed feasibility of using injection forging to replace the multisteps forging and hence, reducing the production steps.

[2].Injection forging would require a higher forming force to complete the process, compared to that in each step in multisteps forging. This may lead to some issues concerning tool life and forming accuracy to be addressed. However, it is noticeable that the energy requirement for injection forging is less than that for the multisetep forging. If other energy consumption factors such as that for the component/workpiece transfer, that for tool-making, etc. are taken into account, its merit would become more evident.

[3].In terms of forming errors, multisteps forgings may be more accurate than injection forgings, if these were compared by referring to each step of the multisteps forging. With increasing forging steps the dimensional errors may reduce gradually in multisteps forging, due to the reduction of the forging force. It means that the tool design for injection forging would need to take into account forming-error compensation more seriously, e.g. through more accurately controlling the die-bore dimensions and through enhancing the die-set stiffness by prestressing and by using fit-in-purpose tool-materials.

[4]. Due to the metal flow and springback characteristics, the underlying material fold is an issue for multisteps forging of the wheel bolt (as illustrated in Figues 14 to 16). High risks 
for folds are introduced due to the material springback, while some fold risks grow inprocess. The position of folding is critical for a fastener since it may determine where a crack may develop when used in practice. However, such a risk for folding is not evident in injection forging, in section D and d (as shown in Fig. 17).

[5]. As for the grain flow, multisteps forging and injection forging show the similar flow lines in the shank part. However, in the head part, multisteps forging may result in a better flow-line distribution due to a simpler material-flow in each step. It results in mild flow lines with less bending which is beneficial to the component properties. This, of course, depends on the component-form to be achieved. It also indicates that a careful tool-design is needed for injection forging to control the material-flow sequence and hence, control the flow-line distribution.

\section{Acknowledgement}

The authors would like to thank the Ritai (Shanghai) Auto Standard Component Co., LTD for allowing for conducting the forming experiments and for manufacturing the forming-tools for experiments.

\section{References}

[1] T. Takami, "Production Engineering Strategies and Metalworking at Toyota Motor Corporation," in 11th International Conference on Technology of Plasticity, 2014, vol. 81, pp. 5-17.

[2] K. Lange, Handbook of Metal Forming. New York: McGraw-Hill, 1985.

[3] R. M. Cogan, "Hydrodynamic Compression Forging," General Electric Company, 1963.

[4] B. Parsons, P. R. Milner, and B. N. Cole, "Study of the Injection Upsetting of Metals," Journal of Mechanical Engineering Science, vol. 15, no. 6, pp. 410-421, 1973.

[5] K. Dieterle, "Determination of Operational Limits for the Upsetting of Tubes Blanks," Industrie Anzeiger, vol. 97, p. 1653, 1975.

[6] J. C. Hendry and M. T. Watkins, "The Prodcution of Hollow Flanged Components from Bar Stock by Upsetting and Extrusion," National Engineering Laboratory Report 628, 1977.

[7] R. Balendra and Y. Qin, "Material-flow Considerations for the Design of Injection Forging," Journal of Manufacturing Science and Engineering, vol. 119, no. 3, pp. 
350-357, 1997.

[8] R. Balendra and Y. Qin, "Identification and Classication of Flow-Dependent Defects in the Injection Forging of Solid Billets," Journal of Materials Processing Technology, vol. 106, pp. 199-203, 2000.

[9] Y. Qin and R. Balendra, "Computer-Aided Design of Nett-Forming by Injection Forging of Engineering Components," Journal of Materials Processing Technology, vol. 76, no. 1, pp. 62-68, Apr. 1998.

[10] R. Balendra and Y. Qin, "Pressured-Assisted Injection Forging of Thick-Walled Tubes," International Journal of Machine Tools and Manufacture, vol. 35, no. 11, pp. 1481-1492, 1995.

[11] Y. Qin, Y. Ma, and R. Balendra, "Pressurising Materials and Process Design Considerations of the Pressure-Assisted Injection Forging of Thick-Walled Tubular Components," Journal of Materials Processing Technology, vol. 150, no. 1, pp. 30-39, Jul. 2004.

[12] Y. Qin and R. Balendra, "Optimisation of the Lubrication for the Extrusion of Solid and Tubular Components by Injection Forging," Journal of Materials Processing Technology, vol. 135, pp. 219-227, 2003.

[13] Y. Ma, Y. Qin, and R. Balendra, "Forming of Hollow Gear-Shafts with PressureAssisted Injection Forging (PAIF)," Journal of Materials Processing Technology, vol. 167, no. 2, pp. 294-301, 2005.

[14] R. Balendra and Y. Qin, "Injection forging: Engineering and Research," Journal of Materials Processing Technology, vol. 145, no. 2, pp. 189-206, Jan. 2004.

[15] L. M. Alves and P. a. Martins, "Injection Forging of Solid Asymmetric Branched Components," Proceedings of the Institution of Mechanical Engineers, Part B: Journal of Engineering Manufacture, vol. 227, no. 6, pp. 898-907, 2013.

[16] M. Plan, M. Rosochowska, and P. Skakun, "Radial Extrusion of Gear Like Components - Numerical Analysis," Technical Gazette, vol. 20, no. 5, pp. 891-896, 2013.

[17] J. . Choi and Y. Choi, "Precision Forging of Spur Gears with Inside Relief," International Journal of Machine Tools and Manufacture, vol. 39, no. 10, pp. 15751588, Oct. 1999.

[18] Y. Lee, J. Lee, and T. Ishikawa, "Analysis of the Elastic Characteristics at Forging Die for the Cold Forged Dimensional Accuracy," Journal of Materials Processing Technology, vol. 130-131, pp. 532-539, Dec. 2002.

[19] “Tungsten Carbide - An Overview," AZOM. [Online]. Available: http://www.azom.com/properties.aspx?ArticleID=1203. [Accessed: 14-Apr-2016].

[20] H. T. Yeo, Y. Choi, and K. D. Hur, "Analysis and Design of the Prestressed Cold Extrusion Die," The International Journal of Advanced Manufacturing Technology, vol. 18, no. 1, pp. 54-61, Jul. 2001.

[21] Standard Guide for Preparation of Metallographic Specimens, ASTM E3-11. United States, 2011. 
[22] Standard Method of Macroetch Testing Steel Bars, Billets, Blooms, and Forgings, ASTM E381. United States, 2001.

[23] H. Kim, S.-M. Lee, and T. Altan, "Prediction of Hardness Distribution in Cold Backward Extruded Cups," Journal of Materials Processing Technology, vol. 59, pp. 113-121, 1996. 